\title{
RECURSOS GEOMÉTRICOS DE DIBUJO, COMPOSICIÓN Y PROPORCIÓN EN LA PINTURA MURAL DE LA IGLESIA PRERROMÁNICA DE SAN JULIÁN DE LOS PRADOS (OVIEDO)
}

\author{
POR \\ LORENZO ARIAS PÁRAMO \\ "...omnesque has Domini domos cum arcis atque columnis \\ marmoreis auro argentoque diligenter ornauit, simulque cum \\ regiis palatiis picturis diversis decorauit: omnenque Gotorum \\ ordinem, sicuti Toleto fuerat, tam in eclesia quam palatio in \\ Ouetao cuncta statuit.» \\ Crónic a Albeldense. Año 881
}

\section{RESUMEN}

El presente trabajo estudia los procedimientos técnicos apropiados de dibujo, geometría y composición empleados en la ejecución de la decoración pictórica mural de la iglesia de San Julián de los Prados, edificada bajo el reinado de Alfonso II (791-842) en las afueras de la ciudad de Oviedo (Asturias). La pintura mural realizada al fresco, que recubre la superficie de sus paramentos interiores, representa la muestra pictórica altomedieval hispana que más perfectamente conservada ha llegado hasta nuestros días. El estudio se centra fundamentalmente en la composición de los trazados previos incisos a punta seca que delimitan el contorno de las figuras dibujadas y que representan la fase preparatoria más importante del diseño de las pinturas.

I «...y todas estas cosas del Señor las adornó con arcos y con columnas de mármol, y con oro y plata, con la mayor diligencia y, junto con los regios palacios, las decoró con diversas pinturas; $y$ todo el ceremonial de los godos, tal como había sido en Toledo, lo restauró por entero en Oviedo, tanto en la Iglesia como en el Palacio» (Texto de la Crónica Albeldense refiriéndose a la decoración pictórica introducida por Alfonso II en sus iglesias y palacios. Cf. Crónicas asturianas, Universidad de Oviedo, 1985). 


\section{SUMMARY}

This paper studies different appropriate technical procedures - drawings, geometrical and compositive- used in the execution of the pictorial wall decorations of the church of San Julián de los Prados built in the reign of King Alfonso II (A.D. 791-842) in the outskirts of the city of Oviedo. The fresco mural designs that cover the surface of the interior ornaments are the best preserved sample of Hispanic early mediaeval painting to have reachead our age. This study deals mainly with the composition of previous layouts outlined by incision with a dry tip which delimit the shape of the figures drawn; they also represent the most important preparatory stage of the projectual design of the paintings.

\section{INTRODUCCIÓN}

La Iglesia palatina de San Julián de los Prados fue construida a fundamentis bajo el período monárquico de Alfonso II (791-842) en fecha no precisada con rigor por las crónicas altomedievales de la monarquía asturiana. No obstante, su edificación estaría comprendida aproximadamente entre 811-842. Dedicada a los santos mártires Julián y Basilisa, está emplazada en la zona norte del suburbium de la ciudad de Oviedo (Ouetao), extramuros, pues, de la regia sedes ovetense de Alfonso II. Mantiene una planta (figura núm 1) con la estructura basilical predominante en la tipología de las iglesias prerrománicas asturianas, es decir, Nave Central (spatium fidelius) de 10,30 m. de longitud y $7 \mathrm{~m}$. de ancho, con su eje longitudinal orientado oeste-este, y separada de las naves laterales norte y sur por sendas arquerías con arcos de medio punto apoyadas en capiteles imposta, que en número de tres descansan en pilares de sección cuadrada. Al éste se abre un arco triunfal que da acceso al Crucero o Nave Transversal, espacio arquitectónico cuya disposición no encontramos en la distribución espacial del resto de las iglesias asturianas conservadas. Tiene esta Nave Transversal $14 \mathrm{~m}$. de largo por 7 de ancho y una altura de cerca de 11 m.; configura un espacio litúrgico (chorus) que precede al ábside tripartito que remata la cabecera. Al Sanctuarium altaris o Abside Principal se le anexan dos capillas al mediodía y al septentrión. A la Iglesia se accede por un vestíbulo y ésta posee dos habitaciones anexas a las fachadas norte y sur: con comunicación interior abierta a la Nave Transversal. Todo el edificio está rematado por cubiertas a dos aguas con armadura de madera, a excepción de la cabecera tripartita, cuyos ábsides están abovedados con cañón, siguiendo la tipología constructiva de las iglesias asturianas de la época.

La pintura mural que recubre la superficie de los paramentos interiores de la Iglesia palatina de San Julián de los Prados representa la muestra pictórica altomedieval hispana que más perfectamente conservada ha llegado hasta nuestros días. Sus más inmediatos antecedentes, tanto de recursos técnicos como de semejanza y de tradición pictórica conservan unas influyentes raices clásicas. Sus motivos decorativos tienen una estrecha relación con la pintura mural de época romana. No vamos a profundizar en esta línea de investigación sobre los orígenes e influencias a que están sujetas las pinturas de San Julián de los Prados, pues otra es la reflexión y objetivos que nos hemos propuesto en estos momentos ${ }^{2}$. Pero aún hoy el programa pictórico de

${ }^{2}$ Existen diversidad de prototipos que influyen en su estilo, múltiples conexiones o afinidades estudiadas inicialmente por su descubridor Fortunato de Selgas en 1913 (Selgas, 1916). Pero la más profunda y decisiva investigación sería la obra realizada por Helmut Schlunk y Magín Berenguer (Schlunk-Berenguer, 1957). Con posterioridad serían estudiadas de forma parcial y principalmente por Jacques Fontaine (Fontaine, 1973), Antonio Bonet Correa (Bonet-Correa, 1980), Joaquín Yarza Luaces (Yarza, 1984), Isidro Bango Torviso (Bango Torviso, 1988), Victor Nieto Alcaide (Nieto Alcaide, 1989), etc... 

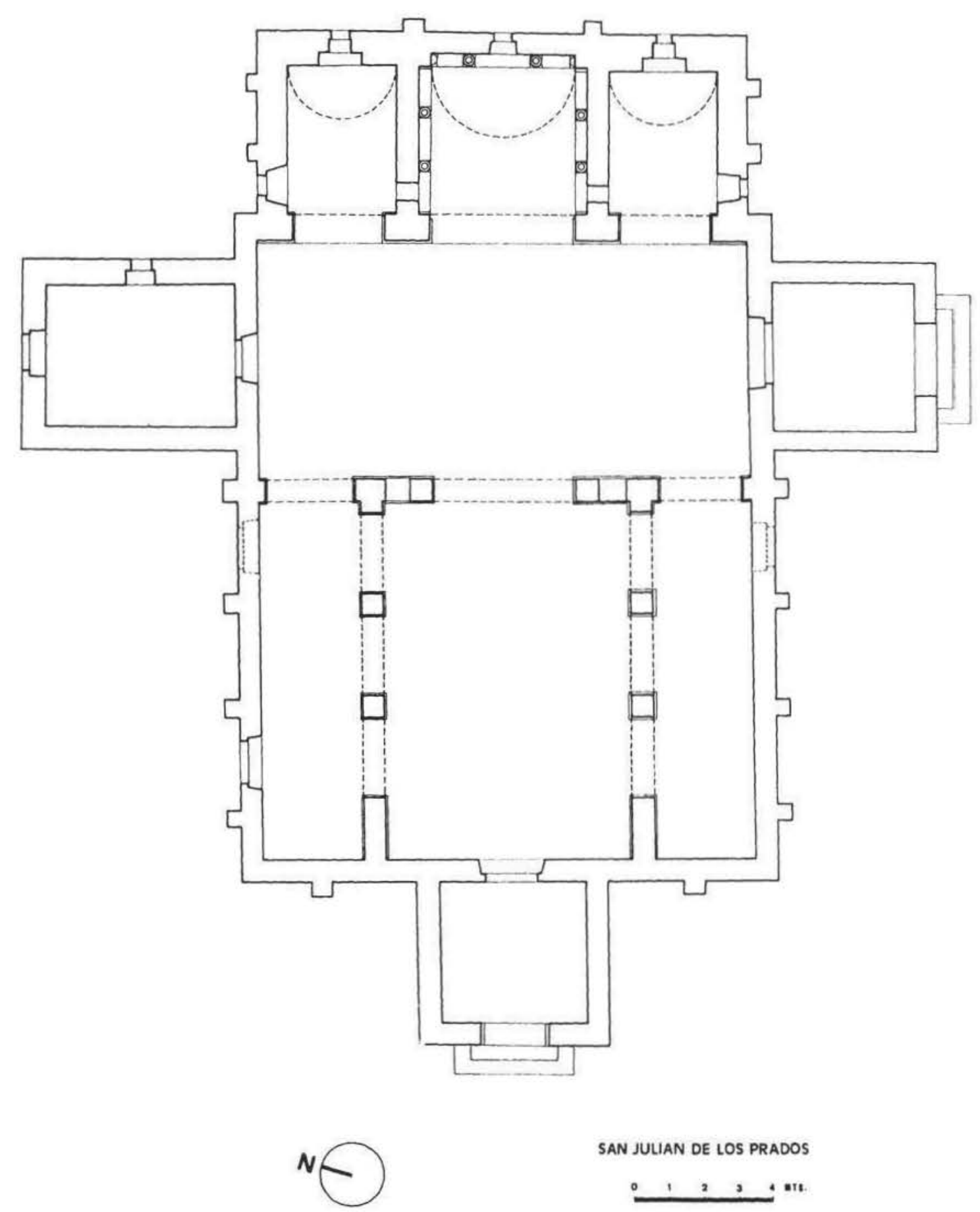

SAN JUUAN DE LOS PRADOS

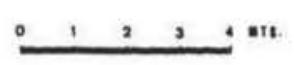

Figura 1.-Planta de la Iglesia de San Julián de los Prados. 


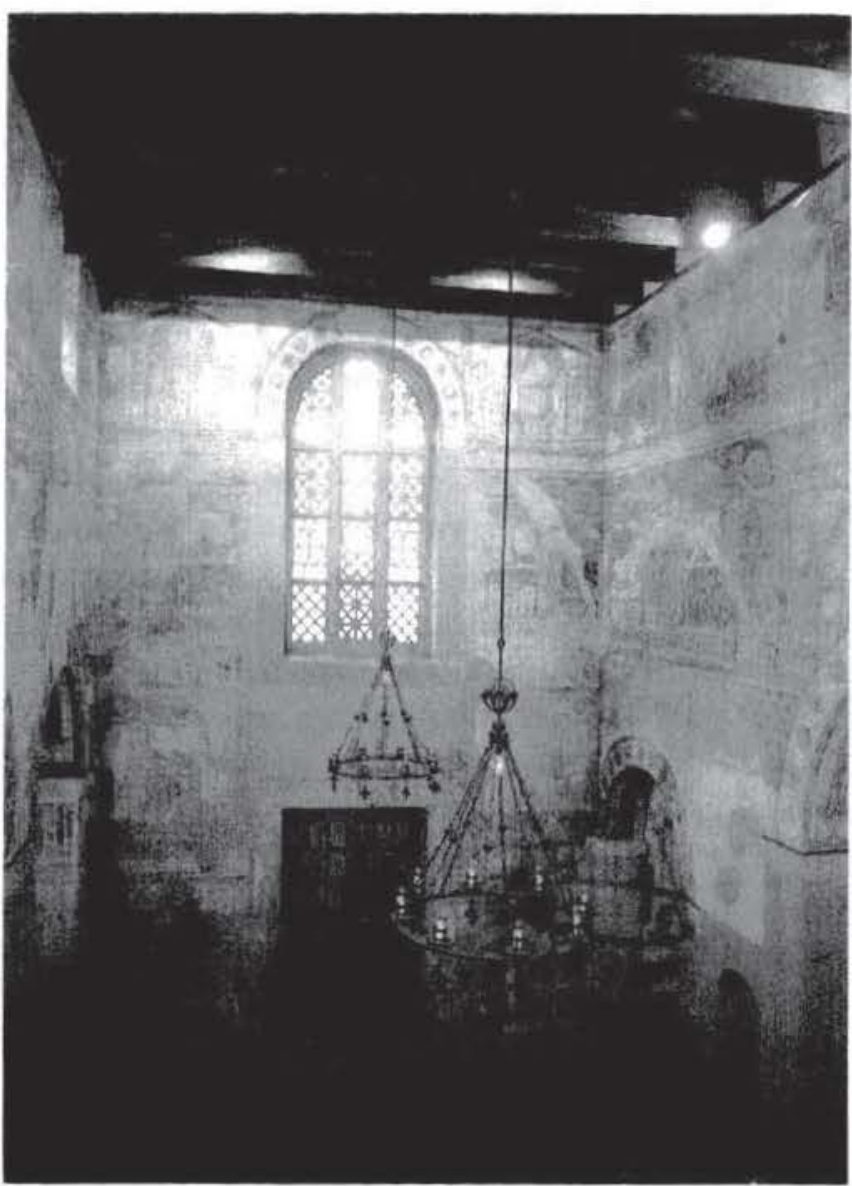

Figura 2.-Vista general de la Nave Transversal hacia el Sur.

las pinturas de Santullano está sujeto en buena medida a conjeturas y actualización en lo que a delimitar los origenes de esta tradición decorativa se refiere. Por ello creemos que sería necesaria una revisión y profundización en el estudio estilístico e iconográfico de la pintura mural de Santullano que actualize la importancia de los prototipos, sus influencias, conexiones estilísticas y grado de identificación e inspiración con el mundo hispanovisigodo y romano, así como el paralelismo con el arte carolingio y el especial atractivo que supone en esa época el interés por la recuperación pictórica del repertorio de representaciones arquitectónicas.

\section{SINNTESIS DESCRIPTIVA DEL PROGRAMA ICONOGRÁFICO DE LAS PINTURAS}

Una síntesis descriptiva del programa iconográfico de la pintura mural de Santullano quedaría dividida en tres niveles:

- Un primer nivel, el más austero de todos, compuesto por un zócalo a nivel de piso con 
su revestimiento pictórico muy mal conservado, a excepción de los restos de las paredes norte y sur de la Nave Transversal. Este soporte reproduce imitaciones de revestimiento marmóreo o crustae policromadas. Decoraciones de rectángulos alternando con bandas y meandros de color rojo y negro así como cuadrados con perfil rojo. Alternativamente se aprecian fajas alargadas en color amarillo oro. Los pilares y pilastras de las arquerías del crucero estarían integrados en este primer nivel así como los pilares de la Nave Central igualmente estucados y revestidos cuya decoración pictórica se ha perdido en su totalidad. Las pilastras correspondientes a la Nave Transversal, en su sector de la cabecera tripartita, conservan una gran riqueza decorativa. Estan realizadas a base de imitaciones de mármol con estriado en color rojo y se encuentran adornadas con pinturas simulando acanaladuras así como imitaciones fingidas de columnas. Respecto a las arquerías de la Nave Central, en la totalidad de sus arcos se han dispuesto medallones entre los que se intercalan haces de hojas contrapuestas. Sus intradoses están recorridos por estilizadas guirnaldas de hojas dispuestas en espiga de variados y ricos colores que surgen de vasos de cuenca gallonada.

- El segundo nivel o Zona Central de pinturas está situado inmediatamente encima del zócalo descrito y registra una extensa decoración de representaciones arquitectónicas. En su parte inferior se imita una cornisa fingida policromada. En el muro occidental de la Nave Transversal se ha representado un recuadro con un motivo ornamental compuesto por círculos entrelazados similar al representado en la pared occidental de la Nave Central. El friso de la zona central nos ofrece un registro de marcos arquitectónicos con una sucesión de edificios ensamblados alternativamente por perspectivas arquitectónicas y compuestos por columnas decoradas con capiteles corintios y pilastras estriadas adosadas a las mismas. Estos se rematan alternativamente por un entablamento superpuesto a un simulado techo de estructura leñosa, mientras que en otros edificios el remate constructivo lo configura un frontón con pequeñas construcciones laterales. En el interior del marco arquitectónico se representan cortinajes recogidos en ambos lados de las pilastras que nos descubre un amplio repertorio de pequeñas edificaciones: en unos encontramos edificios con una planta baja cuya fachada está rematada en un frontón; en otros una construcción central en cuyas fachadas laterales se abren puertas dispuestas frontalmente pero con el cuerpo del edificio siguiendo una técnica de perspectiva con inclinación de $45^{\circ}$. La excepción a esta distribución se encuentra en las paredes norte y sur de la Nave Transversal y en la pared oeste de la Nave Central. La disponibilidad de mayor espacio en sus paredes permitió reproducir grandes edificios que semejan palacios. Las peculiaridades de estos difieren de los correspondientes a la Zona Central. Dos columnas con capiteles corintios flanquean el marco arquitectónico rematado por un entablamento y el correspondiente frontón. Tienen igualmente grandes cortinajes recogidos a ambos lados que descubren una espléndida edificación. Uno de los edificios, repetido cinco veces, es de mayor envergadura que el resto de los edificios pequeños, tiene visión frontal con dos puertas de acceso y cortinajes recogidos a ambos lados. Está rematado por tejado a dos aguas y coronado por una fachada de corta altura en la que se abren seis ventanas. El otro edificio, no repetido, se compone de dos niveles de planta con cuatro huecos abiertos en cada una de ellas, flanqueados por columnas. Se representa una puerta abierta en el lado derecho de la fachada, y en la parte posterior del edificio sobresale otra edificación donde se disponen cuatro ventanas. Se remata la construcción con un frontón y un tejado también a dos vertientes.

- El tercer nivel, o zona superior de ventanas, contiene representaciones arquitectónicas de palacios, las cuales se repiten de forma alternativa. En unos, en su zona central a modo de 
patio, se ha situado un estilizado árbol y en la parte superior un vaso del que surge una guirnalda con flores. En su parte central está rematada su estructura con un frontón, y a ambos lados se encuentran sendos huecos alargados con cortinajes recogidos hacia un lateral. El conjunto queda flanqueado por columnas con capiteles corintios. Otro tipo de representación palaciega está enmarcado por sendas columnas sobre las que se asienta un frontón, estando dos de sus columnas centrales rematadas por un arco de medio punto. Su interior está subdividido en dos niveles: en el inferior se han representado cuatro columnas con una puerta central y en el superior se remata por un triángulo de lados curvos. Otra de las edificaciones está flanqueada por columnas con capiteles de tradición corintia y rematada por un entablamento superior y un frontón el cual encierra una ventana con arco de medio punto. Prácticamente el sector central del marco está cubierto por el despliegue de una cortina de color amarillo oro, y a ambos extremos de la misma y entre las columnas se encuentran sendos jarrones de delgado cuello. De ellos surgen plantas con esquematizadas hojas de color y flores con hojas más pequeñas. Se reproducen asimismo cuadros con cortinajes desplegados en su totalidad y recogidos en forma de pliegues sostenidos por cabalgaduras.

Destaca de forma especial, en este nivel superior, la representación de la cruz de la Anastasis, la Vera Cruz. Carece de pie y se encuentra reproducida bajo un arco decorado con óvalos apuntados simulando piedras preciosas. Dicho arco descansa sobre dos columnas de similares características que las de los marcos arquitectónicos ya descritos de la Zona Central. En todo el conjunto predomina un color amarillo oro. En la cruz aparecen representados el Alpha y la Omega apocalípticos. Sus brazos están rematados en sus extremos por formas redondeadas. En su parte inferior, a ambos lados, se colocan sendos edificios, Belén y Jerusalén, con una puerta de acceso lateral y tres huecos rematados con arcos de medio punto, de los cuales penden cortinajes recogidos hacia uno de los lados.

Por encima de este último nivel recorriendo todo el perímetro de la parte alta de las paredes (si bien en la actualidad se conserva solamente en las paredes oriental y occidental de la Nave Central) está representado un friso de modillones con perspectiva en «espina de pez». Asimismo, en los frontones occidental y oriental de la nave central, se conservan aún, y por encima de este friso, un conjunto decorativamente policromado de vasos situados encima de pedestales de los que surgen hojas con diversas formas de flores y ramas en esquematizada representación.

En cuanto a la decoración pictórica de la cabecera tripartita, a excepción del Abside Central, las otras dos están decoradas con la representación en sus paredes norte y sur de arquerías ciegas fingidas, siendo sólo arquitectónicas las correspondientes al Abside Central. En la parte superior de esta arquería se ha representado un friso de modillones en perspectiva de similares características a los ya descritos. Los motivos de la decoración pictórica de la bóveda central lo componen un conjunto casetonado en el cual se representa una alternancia de círculos y cuadrifolios asimétricamente dispuestos. Los cuadrifolios quedan configurados con cuatro círculos tangentes, en el centro de los cuales se inscribe un cuadrado. En su interior se dibuja un rosetón de ocho hojas policromadas de diverso color. En las bóvedas de los ábsides laterales la composición está integrada por cuadrados y hexágonos. Los cuadrados conservan en su interior un círculo de guirnaldas de flores y los hexágonos tienen dibujados un rosetón del cual irradian dos filas de pétalos. A su vez, en el conjunto de los tres ábsides, y en su pared oriental, a partir de la parte superior del friso de modillones se ha representado, a modo de lujoso tapiz, un planificado motivo de círculos y óvalos apuntados en asimétrica disposición. Los círculos quedan compuestos, por un rosetón 
interior con ocho pétalos y enmarcados por una fina línea de puntos. El conjunto de las dos figuras geométricas óvalo-círculo está ensamblado por estilizadas figuras rectangulares en cuyo interior se dibuja un trenzado floral. El fondo de todo el conjunto es de tonalidad rosácea.

\section{TÉCNICA, GEOMETRÍA Y COMPOSICIÓN DE LA PINTURA MURAL}

Con este estudio pretendemos reflexionar sobre los procedimientos técnicos apropiados de dibujo, geometría, composición y proporción, así como los criterios estéticos empleados en la ejecución de la decoración mural de Santullano. El conocimiento y aplicación de los mismos influirá decisivamente en el acabado pictórico decorativo que recubre la superficie mural del interior de la Iglesia de San Julián de los Prados.

A su vez, la técnica pictórica empleada, los trazados previos incisos a punta seca que delimitan el contorno de las figuras dibujadas, así como el estudio de los procedimientos aplicados en la fase proyectual del diseño de la decoración mural, revisten una especial y relevante importancia para el conocimiento y valoración de las influencias culturales recibidas ${ }^{3}$. Con ello se permite profundizar en la evolución y la transmisión de los conocimientos teóricos, estilos y técnicas aplicadas por los diversos talleres, constituidos con posterioridad al de Alfonso II, en los programas pictóricos desplegados en el conjunto de las iglesias prerrománicas que integran el ciclo artístico asturiano.

La «línea pictórica»supone un ordenamiento intelectual en el cual subyace la preocupación por realizar una construcción geométrica cuyo principal objetivo se encuentra en la búsqueda de la belleza y la regularidad interna de la obra. Por medio del arte de la «Geometría», basada en el compás, la regla y los variados instrumentos de medición, brotarán figuras y «arquitecturas», todo un realismo pensado que simbolizará y esquematizará a partir de los conocimientos científicos de Boecio, Casiodoro, Isidoro de Sevilla,... ideas abstractas en directa correspondencia neoplatónica. Es la geometría entendida como una estructura sirviéndose y organizando su «corpus» a partir del dibujo para configurar la forma y la magnitud de las figuras y los cuerpos. Esta es la geometría «útil» que permitirá realizar y perfeccionar el trabajo del artista y del pintor medieval: "[Artes] incommutabiles regulas habent, neque ullo modo ab hominibus institutas, sed ingeniosorum sagacitate compertas ${ }^{4}$. Y estos principios primarán por encima de lo que podríamos definir como una representación visual directa de la naturaleza: «Pictura autem est imago exprimens speciem rei alicuius, quae dum visa fuerit ad recordationem mentem reducit. Pictura autem dicta quasi fictura; est enim imago ficta, non veritas. Hinc et fucata, id est ficto quodam colore inlita, nihil fidei et veritatis habentia» ${ }^{5}$.

${ }^{3}$ Los trazados previos de la Iglesia de Santullano han sido objeto de reflexión por parte de Helmut Schlunk y Magín Berenguer. (Cf. La Pintura Mural Asturiana de los siglos IX y X, Oviedo. 1957, pp. I68172.)

${ }_{4}^{4}$ «Las artes poseen reglas inmutables, que no fueron en absoluto establecidas por el hombre, sino descubiertas gracias a la habilidad de los inteligentes». (Rábano Mauro, De cleric., instit., 17 (P. L. 107,c. 393).

5 «Pintura es la imagen que representa la apariencia de alguna cosa y que, al contemplarla, nos evoca su recuerdo. Se dice pictura en el sentido de fictura (ficción), pues se trata de una imagen ficticia, no auténtica. De aquí que se denomine también fucata (simulacro), es decir, pintada de un color ficticio, al que no hay que dar crédito, pues no es la verdad» (San Isidoro, Etymologiae, XIX. 16, B.A.C., Madrid, 1983). 
Toda la regularidad compositiva que impregna el soporte pictórico mural medieval de Santullano quedará ordenado de esta forma por líneas horizontales y verticales: una cuadrícula que visualizará la obra completa dibujada preliminarmente y una trama geométrico-aritmética donde el azar pretende ser erradicado y cuya perfección geométrica y armonía entre las partes prevalece como leit motiv en toda su ejecución. En el mundo altomedieval, la pintura recurre a la geometría como eficaz instrumento de conocimiento para materializar gráficamente "aquellas reglas determinadas por la razón con el fin de realizar una forma exterior a su espíritu" (De Bruyne, 1987.218). Espíritu que San Isidoro recogería con precisión: «...Venustas est quidquid illud ornamenti et decoris causa aedificiis additur, ut tectorum auro distincta laquearia, et pretiosi marmoris crustae, et colorum picturae» " ${ }^{\circ}$. La pintura mural de Santullano contrasta en última instancia esa relación de iconicidad existente entre la imagen temporal de un espacio inmediato, real y terrenal y la representación de un espacio trascendente, cuya concepción visual y espacial se escapa de la realidad exterior para configurar un lugar ideal, absoluto. El espacio pictórico de Santullano, su superficie policromada de arquitecturas fingidas, simuladas, presididas por la Cruz del Gólgota suponen una conceptualización de la realidad que establece una barrera entre el mundo sensible, vinculado al espacio temporal del hombre y el mundo sujeto a una concepción atemporal de su existencia; un Universo en modo alguno deducido de la experiencia terrenal, sino fundado en una realidad cuyas imágenes más directas evidencian un alejamiento de toda lógica visual. Por otra parte, dentro de esa conciencia del valor simbólico de la decoración y ornamentación en línea con la venustas isidoriana, Dios sólo será representado por unos inmutables símbolos: La Cruz de la Jerusalén Celeste y el Paraíso Celestial traducen esa evocación plástica. Las representaciones de los Palacios, las arquitecturas regias de los edificios terrenales, esas moradas de ensueño (Fontaine, 1978), las iglesias, suponen ese salto real de la jerarquía política a la organización eclesiástica. Más allá, pues, del revestimiento material de las pinturas murales de Santullano, de sus valores cromáticos, de sus construcciones ilusionistas o de la contemplación y emoción estética de sus perspectivas y lujosas arquitecturas, el tiempo humano presente y futuro se detiene en ese fingido momento y alcanza ahí su sagrado término.

Así, el pintor, de acuerdo con las orientaciones teísticas, debería limitarse a la ejecución material de la obra, mientras que la fijación de los contenidos plásticos sería privativa del teólogo. De hecho los docti (los únicos que estaban legitimados para evaluar los criterios estéticos) proponían a los artifici (los encargados de la creación formal artística) el contenido de sus representaciones.

El pintor del primer medievo asturiano, al igual que el pictor parietarius romano o bizantino, se regía por unos conocimientos o principios de ejecución pictórica en los que las normas y directrices de los maestros del Taller prevalecían sobre las del artista. "Norma, dicta graece vocabulo $\rho \chi \pi \chi v^{\text {ex extra quam nihil rectum fieri potest } " ~}{ }^{7}$. Y en este sentido el Taller de Alfonso II no difería sustancialmente de esas normas heredadas del mundo antiguo, romano o bizantino. De acuerdo con Teófilo, y siguiendo su Diversarum artium aschedula (Theophile, 1980; Dod-

6 «Belleza es lo que se añade en los edificios para adornar y decorar, como los techos artesonados en oro, los revestimientos de mármol y las pinturas de colores». (San Isidoro, Etymologiae, XIX, 9-11; P.L. 82$, c. $672-5)$.

7 «La norma, denominada en griego $\gamma v \omega \mu \omega v$, fuera de la cual no puede hacerse nada bien» (San Isidoro, Etymologiae, XX, 18; P.L. 82, c. 680). 
well, 1961), el pintor, una vez igualada la superficie de estuco enlucida, debía coger el compás y amarrar a cada extremo de sus puntas un palo de madera que permitiera la fijación de un pincel. A continuación pasaría a distribuir y marcar todas las medidas necesarias para la organización de las figuras y composiciones decorativas sobre el soporte mural. El artista debía fijar primero, pues, las proporciones de las figuras sirviéndose de los instrumentos propios del dibujo, básicamente el compás (circinus), la escuadra (norma), la regla (regula), la cuerda para alinear (linea) y la plomada (perpendiculum) (Isidoro, 1983), ejecutando el dibujo preparatorio sobre la pared de acuerdo con la composición pictórica previamente diseñada en boceto, a modo de virtual proyecto. La transposición debía adaptarse a la superficie mural a decorar con un alto grado de fidelidad. Es evidente que dispondría de amplios repertorios iconográficos, en forma de vaciados de cartones y plantillas con decoraciones geométricas y variados detalles de motivos ornamentales, como guirnaldas trenzadas, vegetales, jarrones, vasos, variedad de flores esquematizadas, etc... Aún así, el pintor tendría que reelaborar e improvisar nuevas variaciones de las figuras representadas en los esquemas previos por necesidades de adaptación al dibujo, bien por alteraciones introducidas sobre la marcha en la composición pictórica, bien por acoplamientos y reajustes de las medidas finales. En los trazos lineales de la decoración de la pintura mural de Santullano hemos registrado varios reajustes de este tipo, así como huellas de incisiones a punta seca, rectificadas con posterioridad y desplazadas unos centímetros en dirección a su correcta posición. En acertado juicio de Joan Sureda: «No cabe buscar, sin embargo, una absoluta perfección geométrica, una subordinación total de la forma a la geometría, un esquema de la tiranía de la misma; el ligero, diríamos, fallo del compás, el desviarse de la ortogonalidad hace que la pintura vibre, que la geometría, una de las artes del quadrivium, junto a la aritmética, la astronomía y la música, no convierta la pintura en algo infalible, absolutamente ajeno al sentimiento del riesgo y a la experiencia personal.» (Sureda, 1985. 228). Estas líneas de dibujo que contienen formas geométricas diversas están divididas en proporciones simples de acuerdo con un orden, el cual dirige la división de las zonas o campos de la composición pictórica, en espacios proporcionales según el doble, triple o cuádruple de una magnitud horizontal o vertical, y en la que la materialización de sus medidas respectivas vendrían definidas por la unidad de medida adoptada por el architectus y puesta en vigor por el Taller.

\section{ANÁLISIS DEL DISEÑO Y LOS TRAZADOS PREVIOS}

En la práctica totalidad de la decoración pictórica conservada in situ en la Iglesia de San Julián de los Prados, se ha empleado la técnica de la pintura al fresco. Se aprecia notablemente, y en un perfecto estado de conservación original, la existencia de un trazado previo de dibujo basado en una sencilla, pero útil y eficaz, técnica de incisiones. Las líneas grabadas con un punzón, quizás metálico, han sido ejecutadas con la ayuda de una regla (regula) sobre la última capa del enlucido o intonaco. Esta operación se realizaba sobre el enlucido aún tierno y con posterioridad al repaso con la llana que proporcionaba una superficie adecuadamente lisa. Eventualmente se podía proceder a un bruñido de la superficie final del enlucido con un pulidor (liaculum). Las líneas grabadas por este procedimiento configuran la composición del motivo «ideado» por el autor del programa y ejecutado por el artista o artesano al «tamaño real». El artista debía pintar con los colores preparados siguiendo estas líneas preliminares con las cuales se de- 

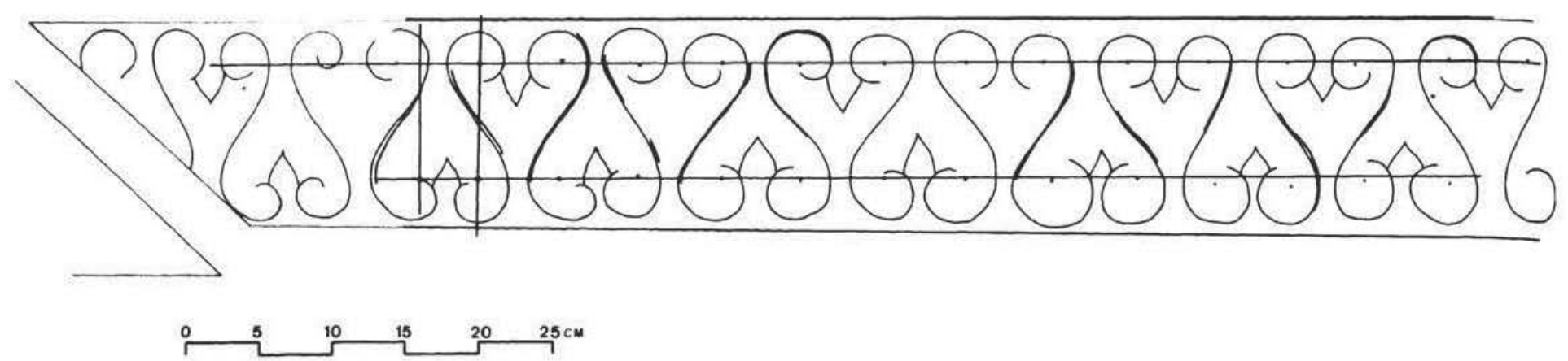

Figuras 3 y 3 bis.-Detalle del trazado previo del techo simulado con motivos en forma de $\mathrm{S}$ en los grandes edificios.

finirá tanto el contorno de los objetos como las zonas de separación de superficies o masas concretas de color. Este procedimiento era conocido y plenamente vigente su utilización en el mundo helenístico, básicamente en el trazado de motivos geométricos, extendiéndose en Roma a partir del tercer estilo pompeyano, aplicándose a múltiples y variados motivos decorativos. Por otra parte, la técnica del grabado de punta seca trazada con un estilete. u otro instrumento de punta fina, utilizada en Santullano sería perfectamente compatible con el uso del trazado pintado. Así, sobre la última capa del enlucido era esbozado el motivo con un pincel el cual había sido previamente impregnado de pintura ocre o roja o de otro color. El sistema, vigente en períodos posteriores del arte Asturiano (Alfonso III y finales de la monarquía asturiana), era ya conocido por los pintores egipcios y griegos en época clásica y helenística y utilizado asimismo en Pompeya (ABAd CASAL. 1982 b).

El método, por medio del cual el artista ejecutaba previamente un esquema abstracto o bosquejo del estudio compositivo final a diferente magnitud, — evidentemente inferior a su tamaño definitivo para luego trasladarlo, con la mayor fidelidad posible, al soporte mural - representa un avance cualitativo de una importancia fundamental en la constitución interna del trabajo del taller pictórico de Alfonso II. La preparación de las líneas verticales y horizontales que configuran una cuadrícula o red de la superficie a decorar, y sobre la cual se va a trasladar la composición decorativa, representa un perfecto y equilibrado conocimiento de la concepción abstracta del espacio geométrico y visual. Esta se encuentra íntimamente unida al desarrollo y generalización de conocimientos teóricos de aritmética y geometría y del uso de instrumentos adecuados de dibujo. El trazado de estas líneas tiene, pues, un decisivo valor de referencia y visión previa de los objetos figurados en su posterior transposición al espacio mural real a decorar. Existe, de esta suerte, una coordinación mutua entre la «concepción espacial real» y la «figuración previa», es decir, la imagen mental que se ha proyectado de los elementos decorativos a componer de su programa iconográfico, y cuyo momento más álgido de madurez sólo lo encontraremos en el Renacimiento, pero que en el período altomedieval que estamos estudiando es aplicado con una visión extraordinariamente premonitora.

El artista medieval, recogiendo las recomendaciones de Vitruvio en su tratado De Architectura (Vitruvio, 1787), de Plinio en su Historia Natural (Plinio, 1947), en los textos de los Map- 
pae clavicula (Mortet, 1907), y en San Isidoro de Sevilla en sus textos de las Etymologiae (Isidoro, 1983), con una fuerte influencia de Plinio en lo que a la actualidad de sus conocimientos pictóricos se refiere, así como en el más antiguo formulario medieval de pintura: el Anónimo de Luccas del siglo VIII-IX (Loumyer, 1920), que data del período carolingio, seguía un orden prefigurado rigurosamente en la ejecución de los trazados sobre el revoque. Este debía de estar bien crespo y grueso, y entonces, tirándolas primero con cuerda, marcaba los espacios dividiéndolos en mitades proporcionales, de acuerdo con el boceto preliminar indicado en los planos generales. La expresión «tirar con cuerda» hace referencia, en la técnica pictórica medieval, al acto de marcar sobre el estuco aún tierno las líneas horizontales y verticales que definirían la composición a ejecutar en la superficie mural. El proceso se iniciaba a partir de la fijación, en un punto previamente elegido en la pared, de una cuerda a cuyo extremo era aplicada a su vez la plomada (perpendiculum). Con el compás de puntas y haciendo centro en un punto de la cuerda, variable éste según el esquema proyectado, se abría el compás con una abertura predeterminada (circinum diducere) y se trazaban círculos (circinatus) hacia la mitad inferior y la superior. De este modo se obtenían intersecciones a ambos lados de la línea vertical que unidas entre sí registrarían la solución pretendida: una línea horizontal. El proceso responde, básicamente, al principio y ejecución del método euclidiano (Heath. 1956) de levantar una perpendicular sobre una línea recta, recogido y descrito en los manuales de pintura medieval (Cennino, 1982). Este método tenía la gran ventaja de prescindir de escuadras o niveles de burbuja, recursos empleados en dibujos y composiciones cuya extensión fuera más reducida y el error introducido mucho menor. El trazado de las líneas generales horizontales y verticales a partir de

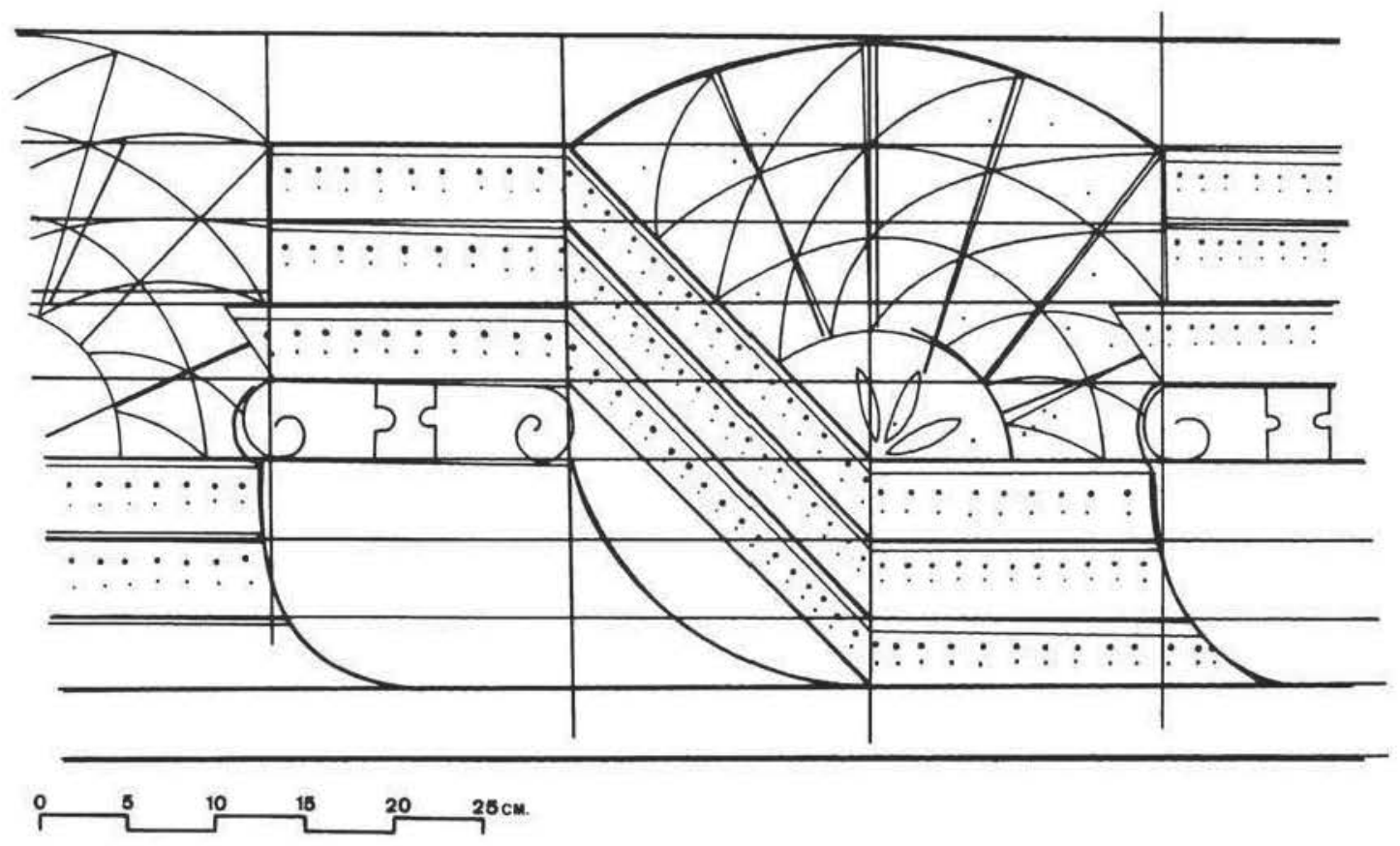

Figuras 4 y 4 bis.-Detalle del trazado previo del friso de modillones con perspectiva en «espina de pez». 
estos puntos obtenidos por el compás, debían ser grabados o marcados en el enlucido húmedo o aún tierno. Para ello se procedía a tensar un hilo o fina cuerda que uniera los puntos obtenidos de color. Seguidamente se procedía a soltarlo de golpe sobre la pared con lo que se obtenía una huella sobre el enlucido. Posteriormente podía ser repasado con regla grabándolo a punta seca; éste sería el caso de las líneas incisas en la superficie mural de la Iglesia de Santullano. En la subdivisión posterior de los esquemas compositivos serían empleados instrumentos mecáni$\cos$ de dibujo comunes a todo taller medieval: las escuadras, el transporte de magnitudes por medio del compás, las reglas y varas de medir, niveles, etc...

A continuación el artista debía iniciar inmediatamente el desleimiento de los colores en agua y proceder a la aplicación inmediata de los mismos sobre el enlucido aún húmedo para que la pigmentación de los colores quedará embebida en el conjunto del revestimiento, formando así una película de carbonato cálcico que uniría homogéneamente los colores a la pared. Es sabido que la mayor dificultad de la técnica al fresco se encuentra precisamente en la rapidez con la que debe ser aplicado el color. El artista, al recurrir a esta técnica, disponía de escaso tiempo para llevar a término su trabajo, por lo que debía poseer una profunda experiencia de los procedimientos técnicos a emplear. El fraguado del enlucido es muy rápido; al disminuir la humedad de la pared los colores no pueden ser aplicados en un espacio dilatado de tiempo. Cualquier corrección pictórica que se pretendiera introducir durante el proceso de trabajo resultaría, pues, arriesgada provocando en muchos casos la sustitución total de la capa de enlucido afectada.

La técnica de la pintura al fresco empleada por los maestros del Taller real de Alfonso II en la Iglesia de San Julián de los Prados sigue una tradición histórica anterior, como ya hemos señalado con anterioridad; recoge en gran medida las reglas seguidas por la tradición artística paleocristiana, romana y bizantina en su tratamiento de las diversas técnicas de revestimiento del soporte mural y preparación de los colores, así como en las prescripciones seguidas en la elaboración y composición de los dibujos previos a ejecutar sobre la superficie de la pared.

El número de capas de enlucido empleadas por el Taller de Alfonso II se ha reducido en número y espesor. Esta variación es coincidente con la disminución progresiva que se experimenta ya en el arte paleocristiano, siendo estas menores en número que en la pintura romana (Abad Casal, 1982 a). Asimismo, en Bizancio la capa preparatoria o trulisación tiene mayor espesor, pero también el número de las mismas es menor. No se ha registrado en ningún momento el tipo de revestimiento descrito y recomendado por Vitruvio y cuya composición estaría integrada por tres capas de arenado encima de la trulisación y otras tres de estuco, siendo la última capa muy fina sometida a un tratamiento de pulido ${ }^{8}$. En la Iglesia de Santullano las diversas capas de enlucido (tectorium) están reducidas a dos: la trullisatio y el intonaco. La trullisatio representa la primera mano de revoco extendida sobre el muro humedecido para sacar la «rectitud» a la pared. Se compone de cal y arenato. "Coronis explicatis parietes quam asperrime trullissentur; postea autem supra trullissationem subarescentem deformentur directiones arenati, ut longitudines ad regulam et lineam, altitudines ad perperdiculum, anguli ad normam respondentes exi-

${ }^{8}$ Cf. Vitruvio Polión. De Architectura. Libro VII, Cap. III. 13. Versión castellana de Joseph Ortiz y Sanz. Madrid, 1787. 
gantur: namque sic emendata tectoriorum in picturis erit species" ". En la Iglesia se Santullano esta primera capa, variable entre 2,5 y $3 \mathrm{~cm}$. de espesor, tiene una composición de un 30 por 100 de arena y un 70 por 100 de cal ${ }^{10}$. A continuación de la trullisatio se extendió una fina capa de 0,5 a $1 \mathrm{~cm}$. aproximadamente de espesor, llamada intonaco, compuesta de arena muy fina y polvos de mármol y cal en proporciones iguales. Sobre ella se aplicaron, ya definitivamente, los colores desleidos en agua. En la técnica del buon fresco no se contemplaba la aplicación del color sobre la capa final del enlucido ya seco. De todas formas en Santullano, al igual que en otras representaciones pictóricas de carácter mural bizantinas o romanas, se han utilizado métodos mixtos, sustitutivos o complementarios, en los que predominaba el uso de colores diluidos con diversos aglutinantes (medium), como cal apagada, aplicados con pincel o por el procedimiento de veladuras. Es lo que suele llamarse fresco seco o medio fresco, pero de todas formas el proceso que se desencadena de reacción química es el mismo por lo que resulta especialmente dificil de identificar y aislar su uso. Aún así, era más fácil de realizar este último método pero con el inconveniente de que la perdurabilidad de sus colorantes es menos duradera. En este proceso se utilizaban igualmente colores en dilución, pero ahora disueltos en agua de cal, y aplicados una vez que el fresco estuviera seco. Su empleo se circunscribía básicamente a un método de retoque de aquellas partes en las que la tonalidad del color lo precisara, bien por la débil intensidad obtenida, bien por corregir posibles errores introducidos durante la aplicación del color.

Ordinariamente se pintaba con rapidez, y como ya hemos mencionado el artista o artesano disponía de un conjunto de planos y modelos iconográficos prefijados de las partes más relevantes del conjunto decorativo a pintar. Ello le permitía visualizar la obra en su generalidad con un alto grado de aproximación real a la composición definitiva.

Los maestros del taller alfonsí trabajarían necesariamente con un indeterminado número de ayudantes, los cuales se repartían el trabajo acorde con el grado de especialización de cada uno. La categoría del pintor altomedieval es difícil de precisar en cuanto a sus competencias específicas. De acuerdo con la inmediata tradición romana habría que tener en cuenta al pictor imaginarius, con una cualificación bastante alta que le permitía pintar con una mayor soltura todo tipo de figuras y motivos pictóricos decorativos. Le seguiría el pictor parietarius, con un nivel inferior de cualificación. Pintaría éste aquellas zonas de la decoración mural que no revistieran excesiva complejidad. Además de estas categorías existirían otros pintores de inferior cualificación, con el grado de aprendiz, cuyo cometido estaría restringido, bien al blanqueo de los revestimientos (los que podríamos llamar dealbatores), o bien a dar la imprimación correspondiente de color al fondo de la pared (los coloratores). Además de estas categorías de pintores habría otros operarios con dedicaciones y competencias variadas: revestir las paredes de estuco, aplicación de argamasas, preparación de pigmentos y colorantes, trazados de los dibujos preliminares, etc...

En las grandes composiciones, como es el caso de la Iglesia de Santullano, en las que era

9 «...Terminadas las cornisas, se dará la trulisación se extenderá sobre ella el arenato, sacando la rectitud horizontal de las paredes a regla y tendel, y la vertical con la plomada, y la de los esconces con la esquadra. De esta forma se preparará una superficie correcta para ser pintada.» (Cf. Vitruvio Polión, De Architectura. Libro VII, Cap. III. Edición de Lipsiae, Sumtibus et typis car. Tauchnitii, 1836. Versión castellana según la edición de Joseph Ortiz y Sanz. Madrid, 1787.)

${ }^{10}$ Agradecemos a José Carlos García Ramos profesor de la Universidad de Oviedo, Dpto. de Geología de la Facultad de Geológicas, el inestimable estudio que nos ha realizado sobre las muestras de revoco procedentes de la pintura mural de la iglesia de Santullano. 


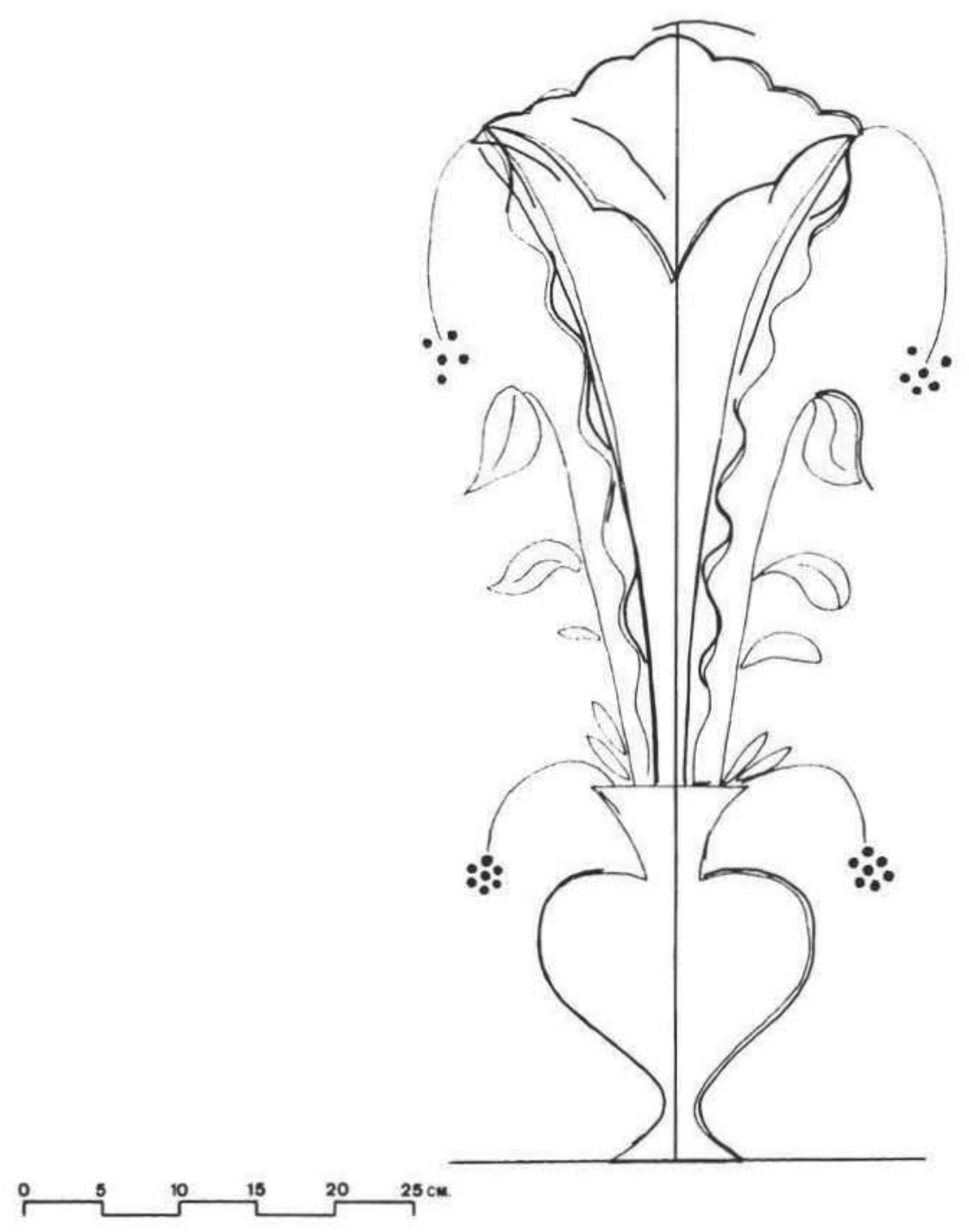

Figuras 5 y 5 bis.-Trazado previo de jarrón con guirnaldas.

preciso trabajar amplias superficies de enlucido, la celeridad en la aplicación de los colores era fundamental pues la rapidez de la carbonatación del revoco está en razón directa con la evaporación del agua que contiene el revestimiento. Ello suponía la estimación de un cálculo del tiempo a invertir, estableciendo un programa de la superficie a preparar con el revestimiento de argamasa y capa de enlucido incluida, así como el tiempo necesario para componer y fijar los trazados preliminares del boceto, las cantidades de pintura a emplear y la duración total que empleará el pintor para llevar a término su trabajo. El estudio de estas variables permitía la determinación de las jornadas de trabajo, es decir las pontatte, o lo que es lo mismo la superficie total que se podía pintar en un día de trabajo. La justeza de la programación permitiría revocar exclusivamente aquella zona de superficie prevista para pintar en un sólo día o jornada de trabajo. El método empleado en la pintura mural de la Iglesia de Santullano ha sido el trabajo por 
andamiadas. Es decir, realizaban el trabajo de revoco y pintura siguiendo la línea de zonas que cubría el andamio (machina), iniciando el trabajo por la esquina superior de la izquierda de la pared con el fin de que las salpicaduras, derrames de pintura y de cal no estropeasen y perjudicaran el trabajo ya pintado. Progresivamente se avanzaría moviendo la estructura del andamiaje de acuerdo con el programa de trabajo diario establecido. El problema derivado de las junturas entre las zonas trabajadas en diferentes jornadas o andamiadas, y la necesidad de que las mismas permanecieran lo más imperceptiblemente posible, debía ser resuelto por los maestros del taller alfonsí de forma muy delicada. En el caso de la pintura mural de Santullano, los bordes siguen exquisitamente las líneas del dibujo vertical, definidas básicamente por el contorno de las columnas y las líneas horizontales, las cuales configuran a su vez los marcos que definen - cada uno de los campos decorativos específicos. De esta forma se establecía una separación clara de zonas de enlucido y color con lo cual la línea de unión o juntura resultaba imperceptible. Los pintores del Taller de Alfonso II debían de tener no obstante una preocupación elemental: al finalizar la jornada de trabajo diaria, debían de desgajar con extremo cuidado el revoco no sometido al tratamiento pictórico, pues al estar carbonatado resultaba ya inservible. Debían además realizar un chaflán en el extremo del enlucido con el fín de que, al aplicar al día siguiente la nueva capa de enlucido, la unión resultase imperceptible. En Santullano estos procedimientos han sido realizados de forma tan cuidada que no son detectables prácticamente.

En opinión de Helmut Schlunk una mirada a los grandes muros de la Iglesia de Santullano «... y a los dibujos previos diseñados a punzón, que aún se aprecian hoy día, nos hace estimar este trabajo como algo de importancia excepcional. Sólo se puede atribuir a un artista que ya hubiese llevado a cabo algo similar en otras construcciones y que estuviese ya familiarizado desde tiempo con su técnica». (Schlunk-Berenguer, 1957. 103). Existe ciertamente un legado

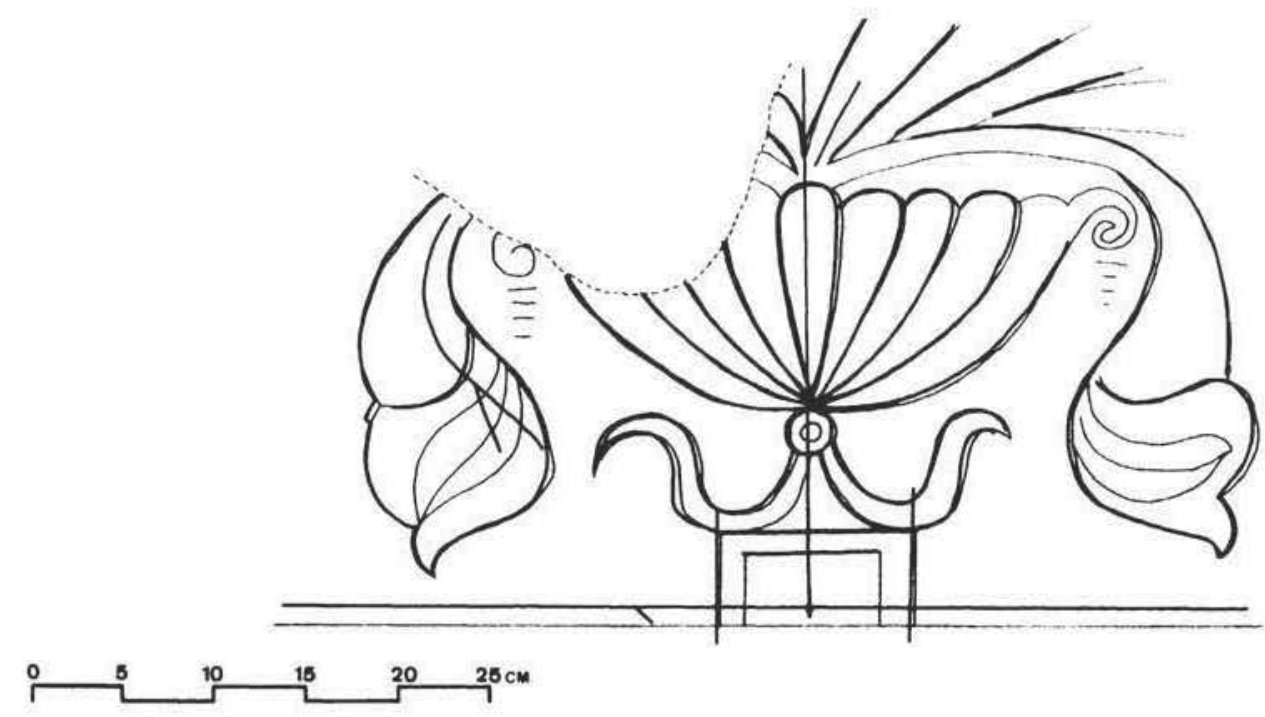

Figuras 6 y 6 bis.-Trazado previo de vasos con flores situados en la parte superior del friso de modillones. 
anterior de tradición romana que está siendo objeto en la actualidad de continuados estudios (Abad Casal, 1977, 1982 a, 1982 b; Ochoa, 1982), y que conserva una absoluta identidad, en lo que a la construcción geométrica del trazado previo de las pinturas se refiere, con los procedimientos empleados en los trazados previos de la decoración pictórica de la Iglesia de San Julián de los Prados. "En la Iglesia de San Julián de los Prados toda la decoración está esbozada mediante líneas incisas, llegando al extremo de trazar ejes de simetría para trasladar las medidas de un boceto previo y de combinar líneas verticales, horizontales y oblicuas para la solución de las perspectivas. Es un testimonio más de la pervivencia de soluciones clásicas. Si se hubiera conservado algún edificio monumental romano de este tipo, posiblemente el esbozo sería muy similar a éste" (ABAD CASAL, 1982 a. 276).

La importante novedad de los trazados previos de Santullano viene dada por ser la única iglesia prerrománica en la que se ha recurrido a esta técnica de dibujo previo inciso a punta seca por parte del taller de Alfonso II. (Si bien recientemente hemos descubierto importantes huellas de trazado previo grabado a punzón en el estuco de la Iglesia de San Pedro de Nora (Nora, Oviedo) edificación construída en el período monárquico de Alfonso II. Creemos que este relevante hallazgo, apunta a una extensión del Taller alfonsí y a la práctica generalizada, y no aislada, de este método en su tiempo.) Así, merced a su extraordinario grado de conservación es posible reconstruir el método de trazado de composición y proporción y su distribución de espacios decorativos y bocetos previos con una fidelidad y precisión que no se ha tenido oportunidad de realizar en ninguna otra edificación. Y ello, tanto en la pintura mural romana conservada actualmente, debido al estado de fragmentación de sus restos pictóricos, como en el resto de la pintura mural prerrománica, al caer en desuso este tipo de técnica de grabado previo con procedimientos mecánicos en los talleres posteriores al período monárquico de Alfonso II, y recurrir a la técnica de la sinopia. Método que consistía en la realización de un dibujo con ocre u otro material colorante, realizado sobre la segunda capa del revoco y que al transparentar sobre el enlucido final cumplía las funciones de guía del trazado final para el pintor. Hemos de hacer constar, no obstante, que en la Iglesia de San Salvador de Valdediós (Villaviciosa, Asturias) construída por Alfonso III en el 893, hemos detectado también surcos del trazado previo grabados a punzón en parte de los restos de pintura conservados, lo que puede apuntar a una pérdida del uso de este sistema no tan radical como hasta ahora se venía sosteniendo. Por otra parte, los restos de pintura mural posteriores al ciclo alfonsí son escasos, y buena parte de los mismos se conservan en condiciones delicadas, y en gran medida deteriorados, con lo que ello supone de dificultad en la interpretación de sus trazados previos.

Las líneas de dibujo grabadas en la superficie de las paredes de la Iglesia de Santullano conservan un orden jerárquico que trataremos de exponer sucintamente. Todas las incisiones definen el esquema previo del programa iconográfico al que se ha recurrido para delimitar el entorno geométrico de las figuras. Dentro de la relativa complejidad de su trazado se observa inicialmente una agrupación de tres tipos de trazado:

* Un primer grupo definiría los Ejes de Simetría verticales y horizontales, mediante los cuales quedarían fraccionados campos decorativos concretos (figuras 9 y 18) facilitando así la distribución general de la superficie de la pared. Como se obseva en la figura estas líneas de sime- 
tría cumplen una función compositiva primordial de referencia en la posterior fijación de la trama geométrica y distribución de las retículas de proyección sobre el revestimiento mural. Permiten transportar las diferentes medidas consignadas en los diferentes bocetos y diseños previos trazados con anterioridad a menor magnitud.

* Un segundo grupo lo configurarían lo que podríamos denominar trazados directores (figuras 10 y 19). Estos constituyen el dibujo correspondiente al trazado preliminar de los frisos de edificios de la zona central de la Nave Transversal y de la Nave Central. Este friso con decoración arquitectónica está repetido rítmicamente y el grabado preliminar a punta seca define de forma extremadamente nítida las columnas decoradas así como el entablamento, las pilastras y el frontón. También se encuentra en este grupo el tercer nivel de ordenación espacial de la pared mural: la que hemos denominado Zona Superior o de ventanas. Aquí el dibujo previo a punzón definiría las líneas principales horizontales y verticales de los diversos palacios que recubren el espacioso panel decorativo superior. Aquí se incluiría igualmente la Cruz de la Anastasis que preside centralmente cada pared transversal de la Iglesia. Las incisiones delimitan tanto el contorno y los vértices del dibujo final como el propio eje de la Cruz y de las columnas.

* El tercer grupo estaría definido básicamente por los trazados auxiliares verticales, horizontales y oblicuos (figuras 11 y 20) que hacen posible la representación previa, tanto de las soluciones perspectivas en «espina de pez»" de los frisos de modillones (en la figura 4 se representan los trazados previos de un tramo del friso. Ver asimismo la figura 7) como de las representaciones geométricas del piso del zócalo con imitaciones de intarsia y grecas. Asimismo se encontrarían en este grupo los intradoses de los arcos decorados con vasos y motivos vegetales, y en los que muchos de sus trazados serían realizados sobre la marcha. También encajan las decoraciones de octógonos y losanges alternados los cuales recubren parte de los muros de las naves laterales, así como los múltiples motivos decorativos que configuran la composición interna de los paneles como es el caso de los jarrones con guirnaldas, uno de cuyos detalles se refleja en la figura 5 ó el conjunto policromado de vasos de los cuales surgen hojas con flores representándose un detalle de su trazado previo en la figura 6 . En este grupo quedan incluidos los trazados de las bóvedas de los tres ábsides que configuran la cabecera tripartíta, e igualmente los pequeños edificios representados en el interior de los palacios de la Zona Central de la superficie mural de cada pared de la Nave Transversal y la Nave Central. Es notable la precisión de los dibujos incisos previos que definen el contorno de los edificios prefigurando la forma final de los mismos (ver el conjunto de dibujos de las figuras 26 y 27 y de la 30 a la 33). Tanto en este grupo como en los precedentes se encuentra perfectamente conservada la huella de haber recurrido al uso del compás de puntas o de pincel, así como la huella de los surcos pertenecientes al trazado de círculos realizados para la obtención de un dibujo geométrico circular específico.

El sistema de trazados previos que "prefigura» la composición decorativa pictórica, como ya hemos mencionado, responde a un programa iconográfico "pensado» previamente y proyectado a una escala menor para, con posterioridad, dibujarlo a su magnitud real sobre el paramento una vez aplicada la capa final del enlucido. Se puede confirmar que los dibujos, que delimitan el contorno de los diversos motivos arquitectónicos y decorativos, han sido trazados en

1 La perspectiva de «espina de pez», estudiada de forma especial por Erwin Panofsky (Panofsky, 1975), se mantiene en la pintura occidental hasta el descubrimiento y difusión de la «perspectiva científica» renacentista. 


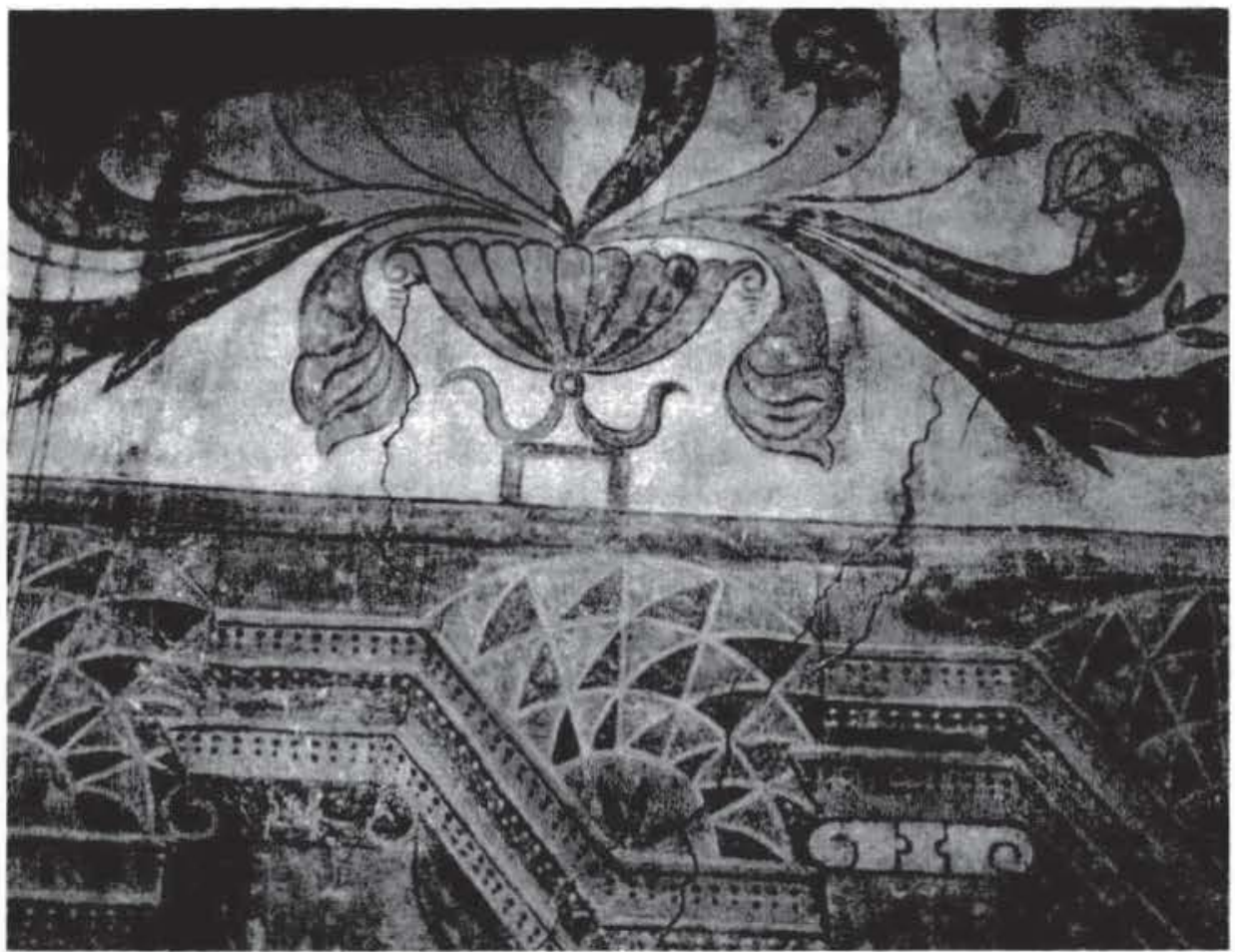

Figura 7.-Detalle del friso de modillones con perspectiva en «espina de pez». En su parte superior se observan los vasos con flores y motivos vegetales.

su casi totalidad sobre líneas incisas previas. La división en tres grupos expuesta más arriba nos permitirá estudiar con mayor fluidez y claridad la transposición del boceto previo a su escala real analizando así con mayor precisión las diversas fases del trabajo y cómo fueron estas desarrollándose sucesivamente.

El estudio geométrico-proporcional utiliza en sus cálculos el sistema metrológico basado en el pie de $0,30 \mathrm{~m}$. El cálculo se ha realizado a partir del procesamiento de un pormenorizado número de dimensiones deducidas del repertorio pictórico mural. Del conjunto de medidas seleccionadas se ha realizado la media aritmética y la desviación standar de las mismas, obteniendo el valor de un pie (pes) de $0,30 \mathrm{~m}$. unidad básica de medida empleada en la ejecución de los trazados (figura 13). El pes se encuentra integrado dentro del sistema metrológico romano de medidas.

\section{ANÁLISIS DE LA PARED OCCIDENTAL DE LA NAVE TRANSVERSAL}

* Por lo que al primer grupo se refiere analizaremos, como ejemplo expresivo, la pared occidental de la Nave Transversal (figura 8). En este lienzo se ha trazado un esquema preliminar de líneas horizontales paralelas a diversa altura; (A-A'; B-B'; C-C' y D-D' con una dimensión longitudinal total de $\left.14^{\prime} 10 \mathrm{~m}\right)$ pero manteniendo entre sí una equidistancia regular $(A-B=7$ pes: $\mathrm{B}-\mathrm{C}=7$ pes $; \mathrm{C}-\mathrm{D}=5$ pes $\mathrm{y} \mathrm{D}-\mathrm{E}=14$ pes $)$. Estas líneas tienen una finalidad muy precisa, $\mathrm{y}$ es la 


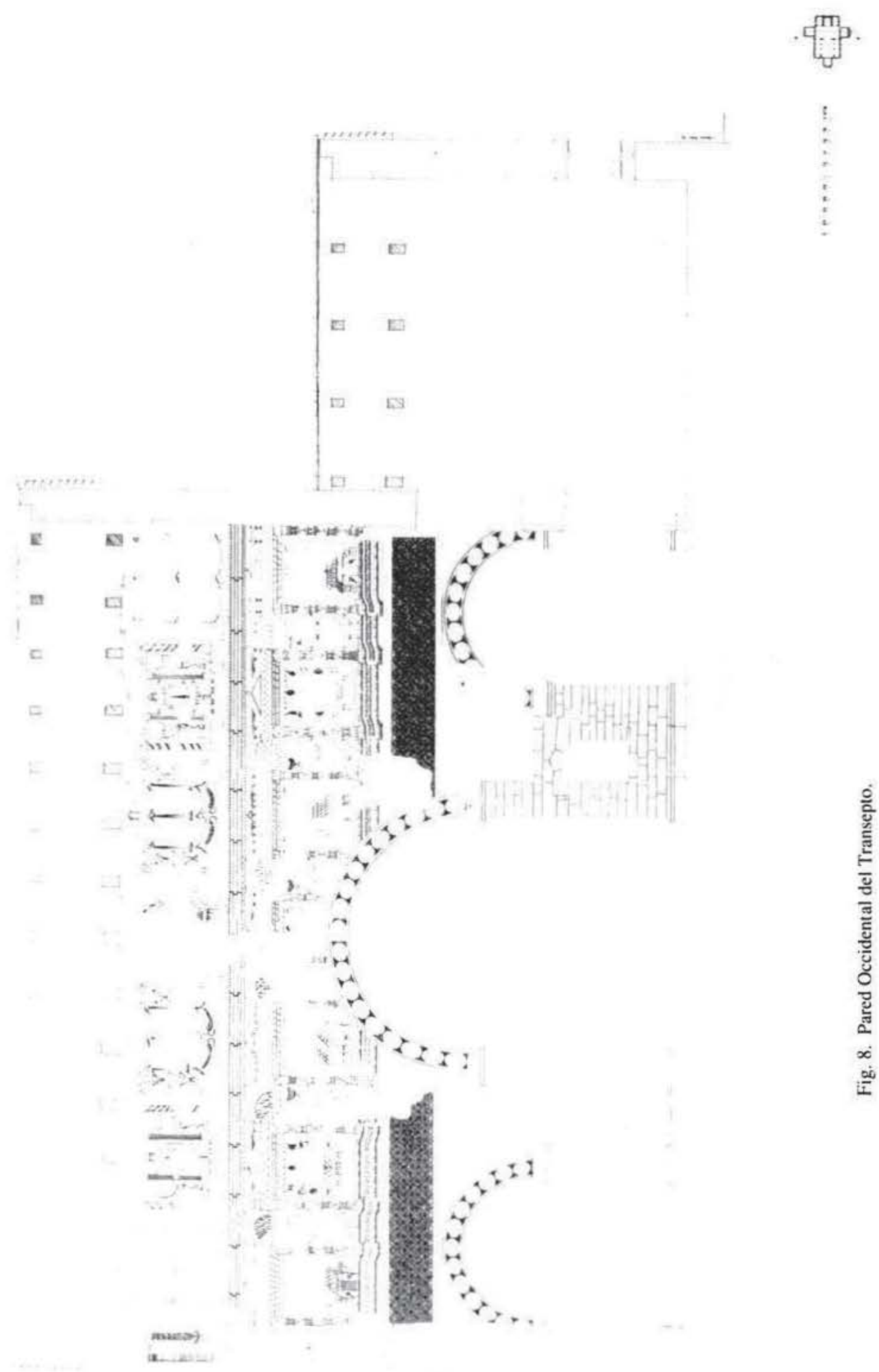




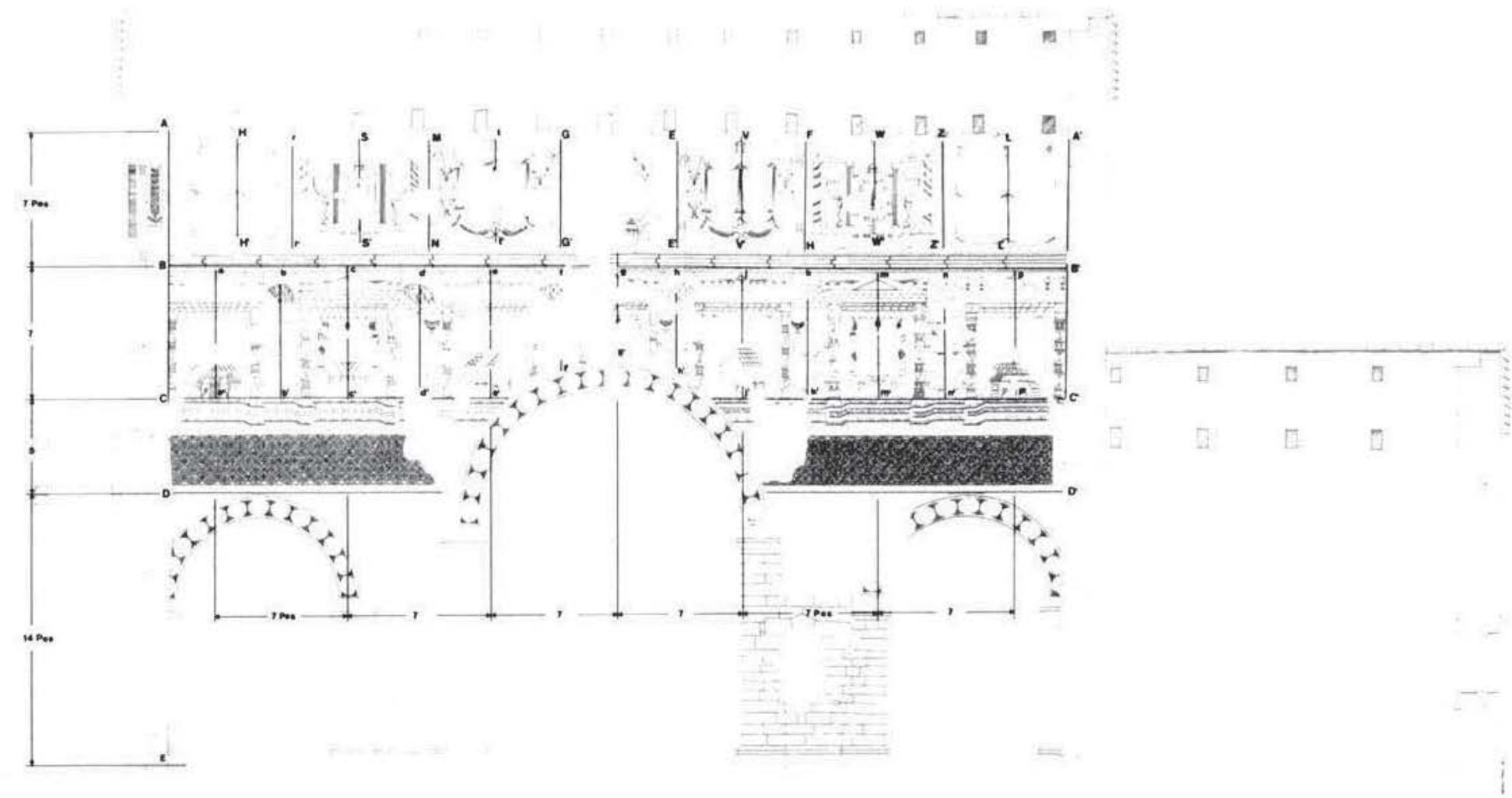

Fig. 9. Pared Occidental del Transepto.

Trazados Previos correspondientes a los Ejes de Simetría 
.
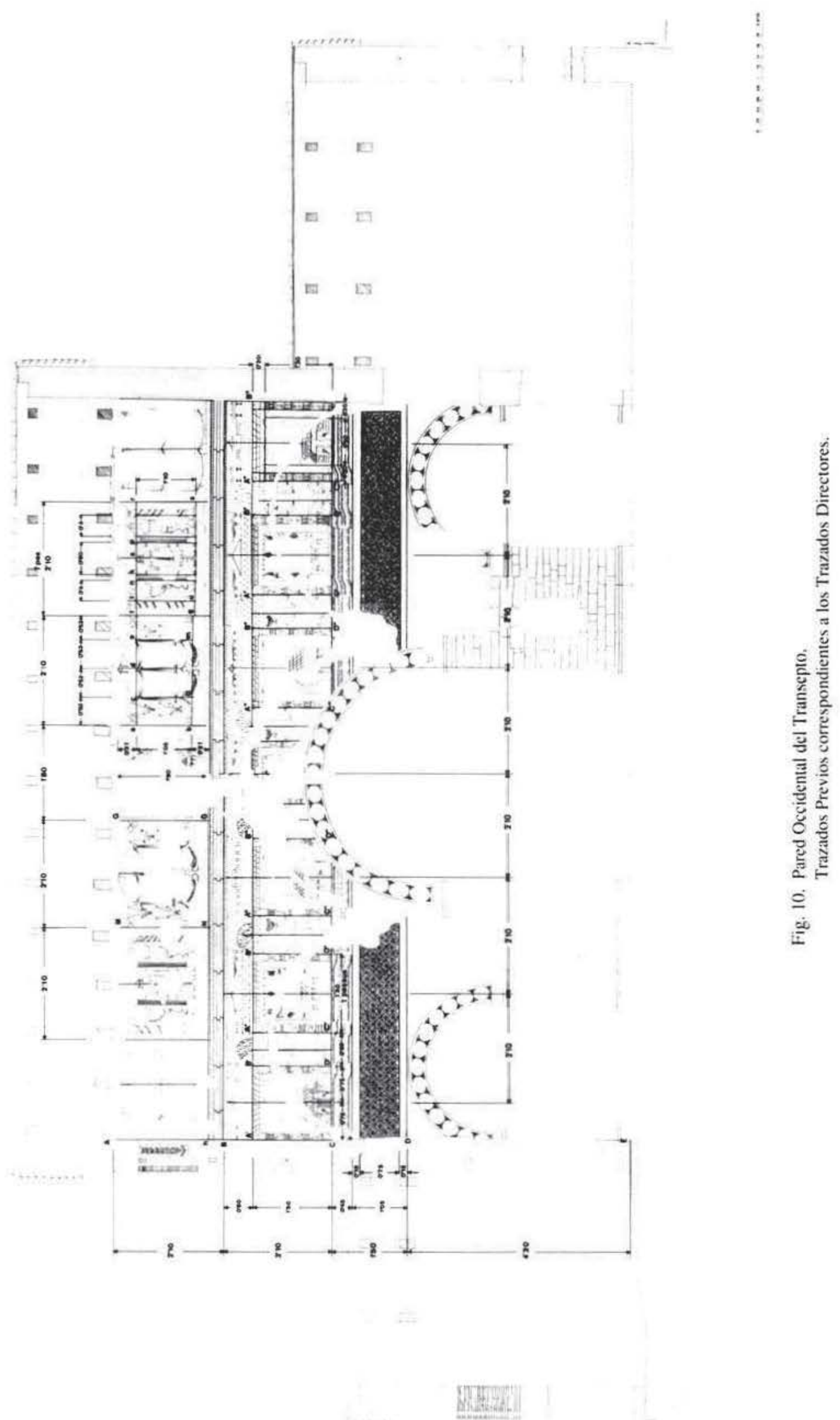

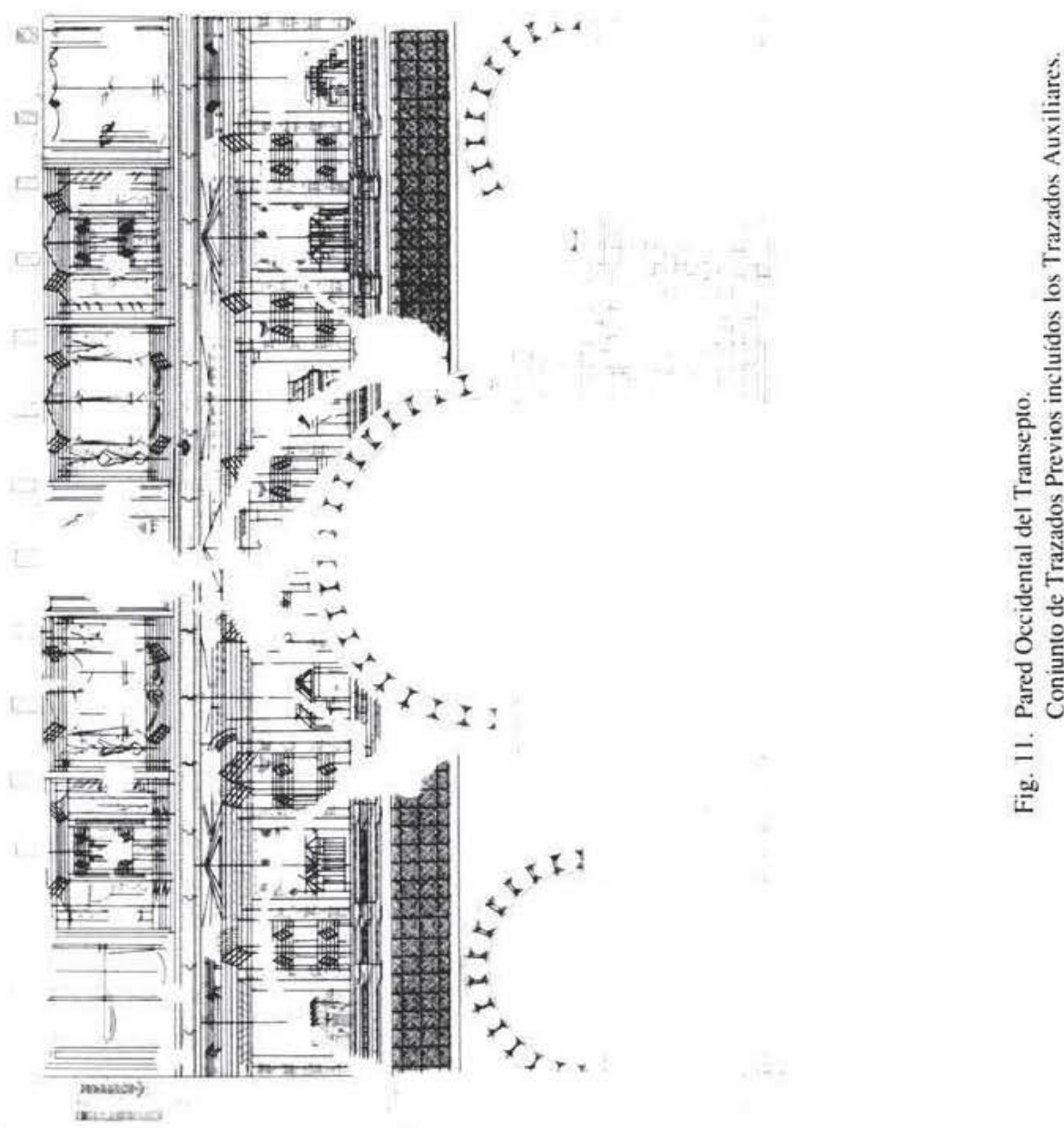

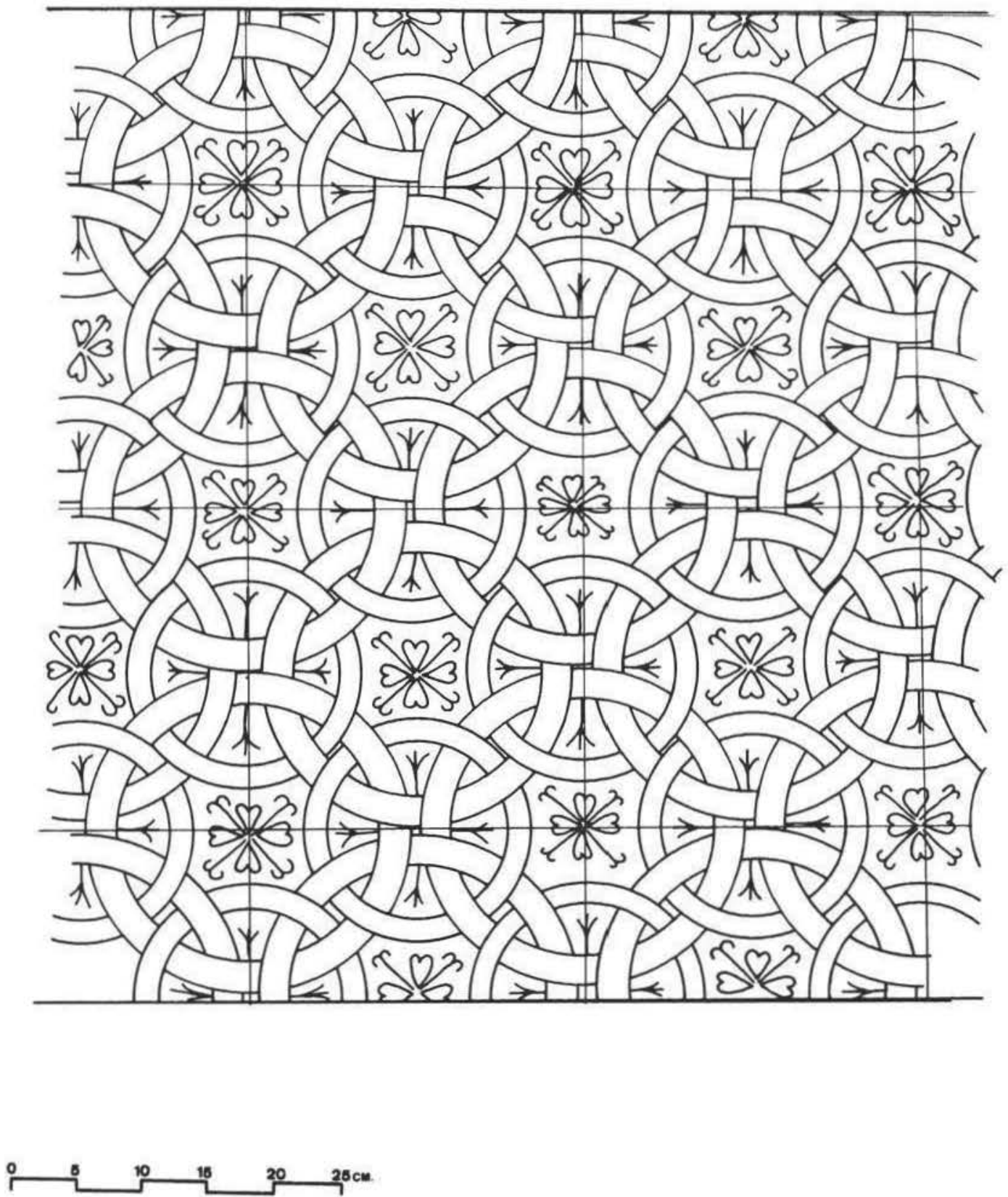

Figura 12.-Detalle del trazado previo de los círculos entrelazados. 


\begin{tabular}{|c|c|c|c|c|c|c|c|c|c|c|c|c|c|c|c|c|c|c|c|c|}
\hline Decempeda & ' & & & & & & & & & & & & & & & & & & & $200.74 \mathrm{cms}$ \\
\hline Passus & 2 & ' & & & & & & & & & & & & & & & & & & $107.00 \mathrm{cms}$ \\
\hline Gradus & 4 & 2 & 1 & & & & & & & & & & & & & & & & & $73.80 \mathrm{cms}$ \\
\hline Cubitus & - $t$ & $3 \div$ & $1 \frac{1}{3}$ & 1 & & & & & & & & & & & & & & & & $44.30 \mathrm{cms}$ \\
\hline Palmipes & - & 4 & 2 & $1 \div$ & 1 & & & & & & & & & & & & & & & $36.97 \mathrm{cms}$ \\
\hline Pes & 10 & 5 & $2 \div$ & 14 & $1 \div$ & 1 & & & & & & & & & & & & & & $20.57 \mathrm{cms}$ \\
\hline Deunx & o유 & of & $2 *$ & 17 & $1 H$ & $1+\pi$ & ' & & & & & & & & & & & & & $27.30 \mathrm{cmo}$ \\
\hline Dodrans & $13 \div$ & $0 t$ & $3+$ & 2 & $1 t$ & $1 i$ & 14 & 1 & & & & & & & & & & & & $22.41 \mathrm{ams}$ \\
\hline Bes & - & $7+$ & 34 & $2+$ & $1 \mathrm{f}$ & $1+$ & 11 & $1+$ & 1 & & & & & & & & & & & $10.82 \mathrm{oms}$ \\
\hline Sepxunx & 17 & $0+$ & 4 & 24 & $2+$ & $1+$ & $1+$ & $1+$ & $1+$ & 1 & & & & & & & & & & $17.43 \mathrm{cms}$ \\
\hline Semis & $\infty$ & $\infty$ & - & 3 & $2+$ & 2 & $1 t$ & $1+$ & $1+$ & $1+$ & 1 & & & & & & & & & $14.94 \mathrm{cms}$ \\
\hline Quincun $x$ & 2 & 2 & 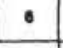 & 37 & 3 & $2+$ & $2+$ & $1+$ & 17 & 17 & $1+$ & i & & & & & & & & $12.45 \mathrm{~cm}$ \\
\hline Triens & 30 & 16 & $7 t$ & $4 t$ & 34 & 3 & $2 t$ & $2 \div$ & 2 & it & $1+$ & $1 \div$ & 1 & & & & & & & $0.90 \mathrm{~cm}$ \\
\hline Palmus & 40 & 20 & 10 & - & 8 & 4 & 3f & 3 & $2 f$ & $2 \div$ & 2 & $1 \frac{1}{2}$ & $1 \frac{1}{5}$ & 1 & & & & & & $7.47 \mathrm{ome}$ \\
\hline Sescuncia & $\infty$ & 40 & 20 & 12 & 10 & $\therefore$ & $7 \frac{1}{5}$ & - & $5 \frac{1}{3}$ & $4 t$ & 4 & $3 \frac{1}{3}$ & $2 \frac{7}{4}$ & 2 & 1 & & & & & $3.73 \mathrm{cms}$ \\
\hline Uncia & 120 & $\infty$ & 30 & 10 & 18 & 12 & 11 & 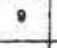 & - & ${ }^{\circ}$ & - & 5 & 4 & 3 & $1 \div$ & ' & & & & $2.40 \mathrm{~cm}$ \\
\hline Digitus & 100 & 10 & 40 & 24 & 20 & 10 & $14 t$ & 12 & $10 \mathrm{f}$ & $0 \frac{1}{3}$ & $\circ$ & of & $5 \div$ & 4 & 2 & 15 & ' & & & $1.87 \mathrm{cme}$ \\
\hline Semiuncia & 200 & 120 & $\infty$ & $\mathbf{3 0}$ & 30 & 24 & 22 & 10 & 16 & "4 & 12 & 10 & $\circ$ & ${ }^{\circ}$ & 3 & 2 & $1 \frac{1}{3}$ & ' & & $1.24 \mathrm{cms}$ \\
\hline Sicilicus & 480 & 200 & 120 & $n$ & $\infty$ & 46 & 44 & 36 & 32 & 20 & 24 & 20 & i6 & 12 & 6 & 4 & 3 & 2 & 1 & $0.82 \mathrm{cms}$ \\
\hline
\end{tabular}

Figura 13.- Tabla de conversión del sistema de medidas romano (basado en Tine Kurent).

de ubicar con precisión los límites extremos superior e inferior de la división jerárquica tripartita introducida en la composición decorativa mural. Todas las líneas en color rojo representadas en el plano se corresponden con trazados de incisiones visibles actualmente en la superficie del enlucido. Recordemos que no se han representado todas las líneas grabadas, sino sólo aquellas que nos interesa estudiar de forma puntual en este apartado por el interés que conservan de fijar las líneas maestras que permiten la ejecución del sistema compositivo de los trazados.

Iniciando la descripción vertical en sentido inferior-superior, desde el suelo hasta el extremo superior, estas líneas incisas de referencia pictórica configuran espacios muy precisos de la decoración mural. Así, el espacio E-D de 14 pes de altura, es decir 4,20 m, nos sitúa el límite inferior de un recuadro rectangular con un motivo ornamental configurado por círculos entrelazados tangentes entre sí y de diverso diámetro y color. Esta franja tiene una altura de 3,5 pes, la mitad de la magnitud de 7 pes que predomina en la altura de los recuadros. En realidad el conjunto decorativo de círculos ensamblados tiene una anchura de franja de 2,5 pes $(0,75 \mathrm{~m}$.) equivalente en el sistema de medidas romano a 1 gradus. El trazado preliminar en forma de malla o red de líneas paralelas y verticales inciso en la pared, y que sitúa los puntos del compás para trazar los círculos, está representado en la figura 12.

Dentro de este tramo D-C se encuentra representada la cornisa fingida policromada sobre la cual se puede observar todo el repertorio de palacios correspondiente a la Zona Central de las pinturas. Esta cornisa contiene motivos geométricos rectangulares con registros quebrados a $45^{\circ}$ y líneas en estrecha franja superior o inferior con motivos de raiz floral. Existe en toda su extensión el surco de los trazos indicadores de las líneas maestras de la decoración (figura 11). La anchura de esta franja es de 1,5 pes $(0,45 \mathrm{~m}$.) equivalente a 1 cubitus.

La Zona Central, acotada por la magnitud B-C de 7 pes y que reproduce el friso de arqui- 
tecturas, ha sido organizada en su composición rítmica y simétrica, a partir de la figura geométrica del cuadrado. Inicialmente 13 Ejes de Simetría geometrizan y actúan como referencia divisoria de su distribución. De estos Ejes de Simetría, 7 pertenecen a los ejes de los Palacios decorados con columnas y rematados alternativamente por frontones y tejados. Estos ejes (a-a'; cc'; e-e'; g-g'; j-j'; m-m' y p-p') tienen una separación entre sí de 7 pes $(2,10 \mathrm{~m}$.) la misma dimensión que en altura conserva el friso de palacios en toda su longitud. Este procedimiento técnico de composición es de una relevancia decisiva; supone que una sencilla trama reticular permite trasladar al soporte mural el diseño general ejecutado a escala, reproduciéndolo con una gran fidelidad compositiva respecto al boceto original.

Este procedimiento será aplicado asimismo en la zona de construcción de los Palacios de la Zona Central, y entraríamos en la descripción de los que hemos definido como segundo grupo o análisis de los trazados directores (figura 10). Estos, en efecto, conservan en su totalidad unas columnas decoradas y rematadas en capiteles de tradición corintia. Cada Palacio nos ofrece una altura de columna de $\mathrm{A}^{\prime}-\mathrm{C}=5$ pes $(1,5 \mathrm{~m}$.) equivalente a 1 passus en el sistema romano de medidas, cumpliéndose este tempo o secuencia rítmica metrológica, en el dimensionado del resto del intervalo columnar $\left(\mathrm{B}^{\prime}-\mathrm{D}^{\prime}=5\right.$ pes; $\mathrm{A}^{\prime \prime}-\mathrm{D}^{\prime \prime}=5$ pes, $\mathrm{A}^{\prime \prime}-\mathrm{D}^{\prime \prime}=5$ pes, etc...$)$. A su vez, la altura de 1 passus ó 5 pes es igual a la distancia existente entre las columnas correspondientes de cada Palacio $\left(\mathrm{C}-\mathrm{D}^{\prime}=5\right.$ pes; $\mathrm{C}^{\prime \prime}-\mathrm{D}^{\prime \prime}=5$ pes$; \mathrm{C}^{\prime \prime}-\mathrm{D} \mathrm{D}^{\prime \prime}=5$ pes, etc..$)$, con lo cual tenemos configurado un cuadrado perfecto de lado 1 passus, que enmarca el diseño y composición general de cada uno de los Palacios.

Esta regla de dimensionado es alterada exclusivamente en el Palacio situado en el Eje central de Simetría. Aquí, la distancia entre sus columnas es de $1,20 \mathrm{~m}$. y no de 1,50 m., medida común del resto de las distancias intercolumnares. Este ajuste obedece a una adaptación del proyecto original a la superficie de la pared. Así, los dos ejes de simetría situados inmediatamente al lado del eje central miden $2 \mathrm{~m}$. entre sí y no los 7 pes $(2,10 \mathrm{~m}$.) perceptivos que debían de tener de acuerdo con la perfecta regularidad introducida en el resto del dimensionado.

En estas construcciones palaciegas el ancho del fuste de la columna de 5 pes de altura tiene valor de $0,15 \mathrm{~m}$., es decir, la mitad de 1 pes. Magnitud que se mantiene con ligeras variaciones en la totalidad de los fustes de los palacios. Igual valor de $1 / 2$ pes $(0,15 \mathrm{~m}$.) tiene la pilastra adosada que sostiene la techumbre con imitación de estructura en viga de madera. La altura de esta techumbre tiene una uniforme medida de $0,20 \mathrm{~m}$. ( 1 bes en el sistema romano de medidas). A su vez, la distancia existente entre las pilastras adosadas es de 3 pes, mientras que la altura del fuste de la columna (igual a la altura total de la pilastra) es de $1,30 \mathrm{~m}$. equivalente a 3,5 palmipes ( 1 palmipes $=0,37 \mathrm{~m}$.). Por su parte, el entablamento apoyado en las columnas con capiteles de tradición corintia, tiene una altura de $0,20 \mathrm{~m}$. Esta magnitud es uniforme, no así la posterior subdivisión en tres bandas, la cual varía en sus medidas.

Estas representaciones de palacios están unidas por edificios en perspectiva, en el centro de los cuales tienen una pilastra estriada de $1,30 \mathrm{~m}$. de altura (3,5 palmipes), sobre la cual descansa un entablamento en forma de ángulo a $45^{\circ}$ de inclinación, superponiéndose la incisión del eje de simetría en uno de los lados de la misma (b-b'; d-d'; f-f'; h-h'; k-k'; n-n'). La anchura de este tramo tiene una medida de 1 gradus $(0,75 \mathrm{~m}$.). La pilastra introduce una división en dos espacios iguales de 1 palmipes cada uno.

La disposición de los diversos espacios o plantas con columnas adosadas, tanto a la pilastra central descentrada como a las columnas de los paneles arquitectónicos contiguos, está subdi- 
vidida igualmente con trazados previos incisos. Sus marcas permiten deducir el dimensionado introducido en sus elementos compositivos en perspectiva tal y como lo reflejamos en el dibujo de la figura 10. En ella las medidas verticales correspondientes conservan el siguiente dimensionado: una altura de 1 palmipes para el primer piso inferior. 2 bes $(0,40 \mathrm{~m}$. $)$ para el segundo piso, 1 pes de $0,30 \mathrm{~m}$. para el entablamento superior y 1 dodrans $(0,224 \mathrm{~m}$.) para la medida del extremo superior, lugar de emplazamiento, a su vez, de la figura de un jarrón. Las dos plantas o niveles del patio que configuran el espacio arquitectónico analizado albergan sendas columnas adosadas a las paredes laterales (en realidad las columnas pertenecientes a las paredes contiguas). En el piso inferior, la altura de estas es de 2 bes y su ancho de 1 palmus $(0,074$ m. ). Por su parte en el piso alto de la columna tiene una altura de 2 bes y el mismo ancho de 1 palmus.

Analizaremos ahora el último tramo A-B de este lienzo occidental de la Nave Transversal (figura 9). Esta franja, a los que hemos Ilamado Zona Superior o de ventanas, tiene una altura de 7 pes $(2,10 \mathrm{~m}$.) magnitud igual, pues, al tramo anterior B-C o Zona Central. Se establece así una secuencia rítmica, ya descrita líneas arriba, de repetición de la magnitud de 7 pes. En la parte inferior de esta Zona Superior de representaciones arquitectónicas se ha introducido un friso ornamental con un ancho cuya medida es variable entre 0,29 y $0,32 \mathrm{~m}$. Hemos deducido una media aritmética de 1 pes de $0,30 \mathrm{~m}$. para la franja. Queda así el resto del dimensionado correspondiente estrictamente a las representaciones arquitectónicas con una medida de 6 pes de altura $(1,80 \mathrm{~m}$.). Magnitud que permanece prácticamente invariable a lo largo de los $14,10 \mathrm{~m}$. de longitud total. Detectamos ciertas desarmonías metrológicas entre las distancias de los respectivos ejes de simetría, consecuencia indudable de los distintos artesanos que han trabajado conjuntamente en la obra. En efecto, en el sector situado a la derecha del Eje Central vertical, los ejes de simetría son una prolongación vertical fiel de los ejes de simetría inferiores situados en la Zona Central de Palacios. Por el contrario, en el sector izquierdo de esta franja superior, los ejes de simetría verticales conservan una pequeña pero variable diferencia entre sus distancias. Esta circunstancia impide que la prolongación de algunos ejes de simetría de la Zona Central izquierda no tengan continuidad en la Zona Superior y tengan una desviación de escasos centímetros. Así, en la figura 9 podemos observar representada la magnitud constante de 7 pes entre los ejes de simetría (H-H'; S-S'; t-t'; U-U' en el sector izquierdo y V'V'; W-W' y L-L' en el sector derecho). La distancia entre los ejes A-h y r-r' del sector izquierdo es de 1,97 m., próximo a los 7 pes, así como la magnitud Z-Z' y A'-A" en el sector derecho de igual magnitud: 7 pes aproximadamente. Estos ejes incisos son fundamentales para redistribuir ulteriormente todo el trazado del programa iconográfico proyectado. Si estudiamos ahora el dimensionado de los cuadros en los cuales se encuentran las representaciones arquitectónicas, observaremos como esta magnitud de 7 pes se repite proporcionalmente también aquí. Entre el eje r-r' y el eje $\mathrm{M}-\mathrm{N}$ existen 7 pes, al igual que entre el M-N y el G-G' o el E-E' y el F-F' o entre el F-F' y el eje Z-Z'. Unicamente el cuadrado central configurado por los ejes G-G' y el E-E' con una distancia entre ellos de 6 pes, se escapa a esta constante de rectángulos de 7 pes de largo por 6 pes de alto. El hecho que encontremos la figura del cuadrado en la Zona Central obedece a que en este espacio está representada la Cruz de la Anastasis, habiéndose adaptado el marco que la contiene a las proporciones de la Cruz.

Las incisiones grabadas a punzón de los Trazados Directores (figura 10) de esta Zona Superior, son claramente perceptibles en el enlucido. Estas definen las líneas principales verticales y 
Figura 14.-Edificio situado en la pared occidental de la Nave Transversal en el cual se observan los trazados previos de ejecución del diseño proyectual.
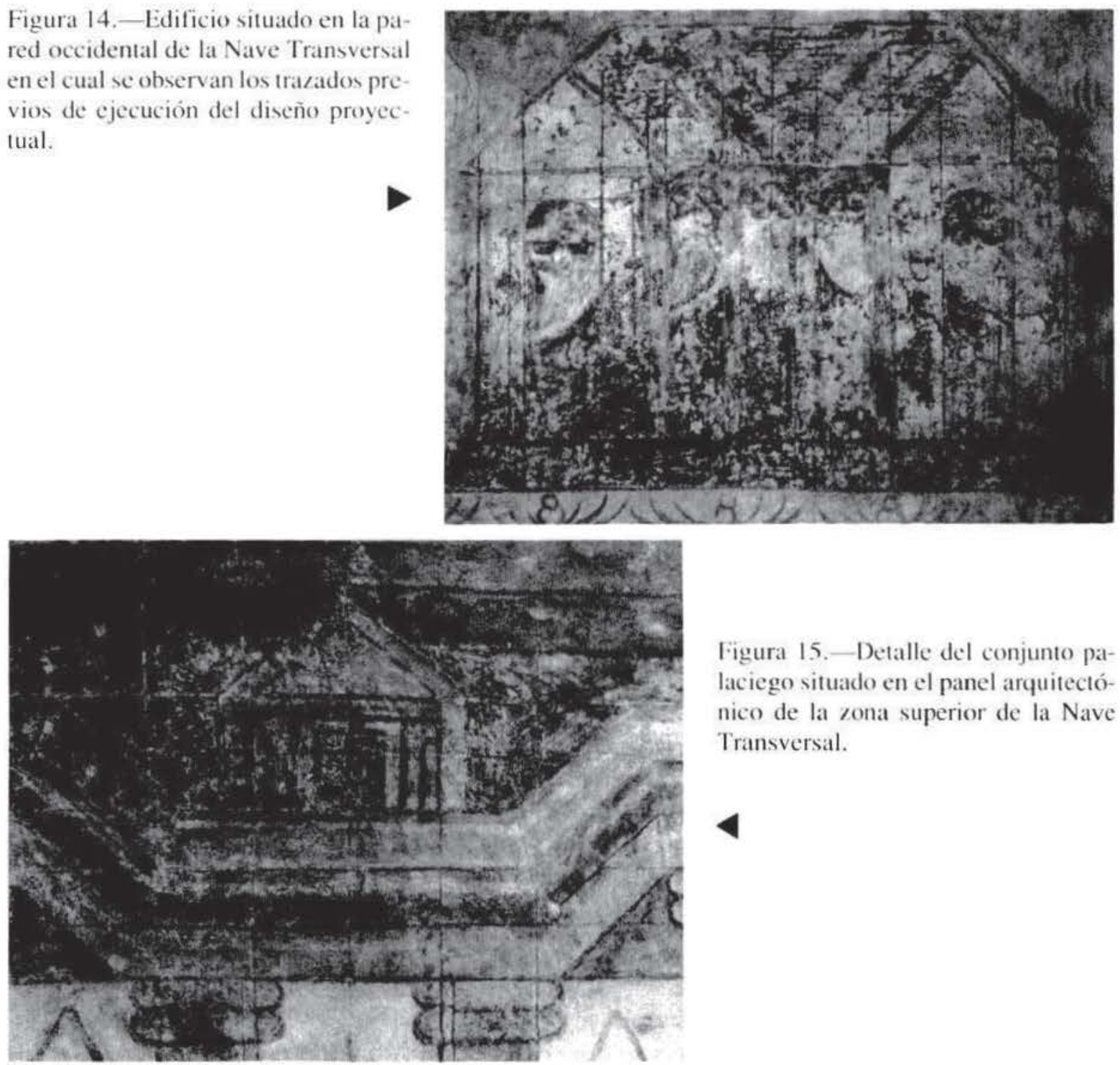

Figura 15. - Detalle del conjunto palaciego situado en el panel arquitectónico de la zona superior de la Nave Transversal.

Figura 16. - Detalle de jarrón con flores situado en el sector izquierdo del panel arquitectónico de la zona superior de la Nave Transversal.

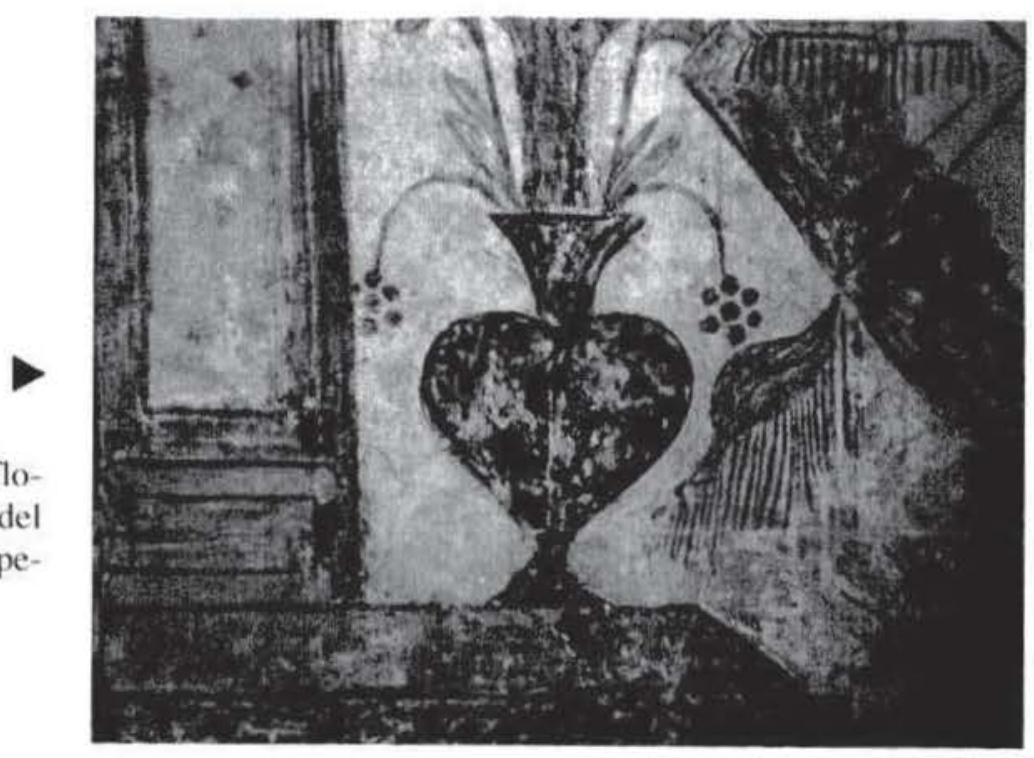


horizontales de la estructura compositiva de los palacios y los distintos elementos decorativos de los marcos arquitectónicos. Así, en el marco configurado por el rectángulo E-F-E'-H, de 7 pes de largo por 6 de ancho, observamos una distribución regida por unas ajustadas reglas de composición y proporcionalidad en sus dimensiones, a la vez que metrológicamente se recurre a magnitudes cuyos valores son múltiplos del valor adoptado como unidad de medida: el pes. En este marco, el lado mayor E-F, de 7 pes ha sido dividido en cuatro partes iguales obteniendo los trazados reguladores del posterior dibujo final. Así obtenemos la partición a-c; c-d; d-e y e-f, de 3 septunx $(0,525 \mathrm{~m}$.) cada una. Respecto a la altura interior a-b y f-g ésta conserva una medida de 3,5 pes ( $1,05 \mathrm{~m}$.), la mitad del largo total del marco arquitectónico de 7 pes y el doble de 3 septunx. (Ver detalle en la figura 16). Las otras dos medidas que subdividen el interior del rectángulo son: el tramo superior E-a, sobre el cual se sitúa el frontón con una altura de 1 palmipes $\left(0,375 \mathrm{~m}\right.$.) y el tramo inferior $\mathrm{b}-\mathrm{E}^{\prime}$ de igual magnitud: $0,375 \mathrm{~m}$.

En ẹl panel arquitectónico contiguo F-Z-H-Z' se han subdividido los diversos espacios que definen las líneas reguladoras de su composición decorativa (figuras 11 y 15) proporcionando inicialmente una magnitud de 2 pes a la distancia intercolumnar central K-P. El ancho del fuste, a su vez, tiene 1 triens $(0,10 \mathrm{~m}$.) y el contiguo intercolumnio 2 bes $(0,40 \mathrm{~m}$.). Cada columna extrema lateral tiene un fuste de 1 quincunx $(0,124 \mathrm{~m}$.). Respecto a la configuración vertical, la altura $\mathrm{f}$ - $\mathrm{g}$ tiene un valor de $1,10 \mathrm{~m}$. equivalente a 3 palmipes. El tramo superior $\mathrm{F}$ - $\mathrm{f}$ también conserva igual medida unitaria de 1 palmipes. A su vez, el tramo inferior $\mathrm{g}-\mathrm{H}$ tiene el valor de 1 pes. La altura de las columnas extremas de fuste decorado con sogueado, conserva una altura total de 3,5 palmipes (1,29 m.). Las columnas interiores, por su parte, miden $1,16 \mathrm{~m}$. de altura correspondiendo 3 pes a la altura del fuste. La zona central de este conjunto palaciego está dividida en dos niveles, configurando una perspectiva arquitectónica. En el nivel superior, sobre el cual se ha representado un estilizado árbol, la altura del espacio flanqueado por columnas mide 1 cubitus $(0,44 \mathrm{~m}$.) mientras que la parte inferior, en la cual se ha representado un pequeño arbusto, tiene una altura de 1 pes.

\section{ANÁLISIS DE LA SECCIÓN LONGITUDINAL HACIA EL SUR}

Esta sección (figura 18) recoge tres lienzos con conjuntos pictóricos importantes. Uno de ellos pertenece a la bóveda del Abside Central decorada con motivos casetonados, en el que se han representado círculos y cuadrifolios alternativamente dispuestos. El segundo lienzo corresponde a la pared sur de la Nave Transversal y el tercero al lienzo sur de la Nave Central.

* Los restos pictóricos que actualmente permanecen en el lienzo sur de la Nave Central se encuentran en un delicado estado de conservación, si bien han tenido un proceso de restauración y ello posibilita que en la actualidad puedan ser estudiados con cierto rigor, pues se conservan las líneas generales de la composición arquitectónica. No obstante en esta zona la densidad de trazados previos es más tenue que en el resto de los lienzos, aún así el estudio metrológico y de composición no se verá afectado negativamente por esta circunstancia. El trazado distributivo de la composición horizontal recurre al método proporcional descrito en la división jerárquica de la Nave Transversal. Así, se mantiene el inicio de la primera franja decorativa, imitación de una cornisa fingida policromada, a una distancia próxima a los 4,20 m., la misma magnitud que había sido ajustada para la Nave Transversal ya estudiada. La distancia en esta oca- 


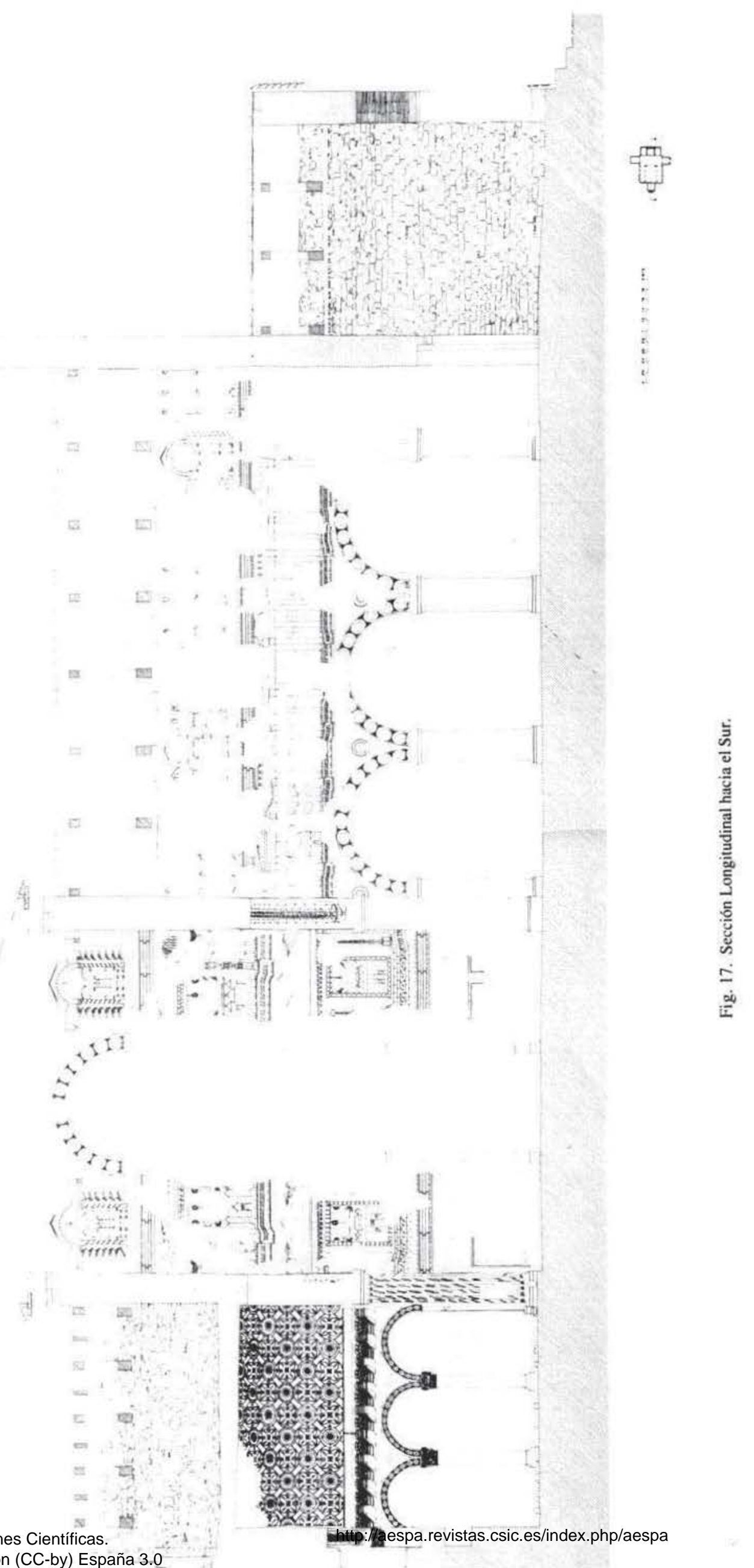




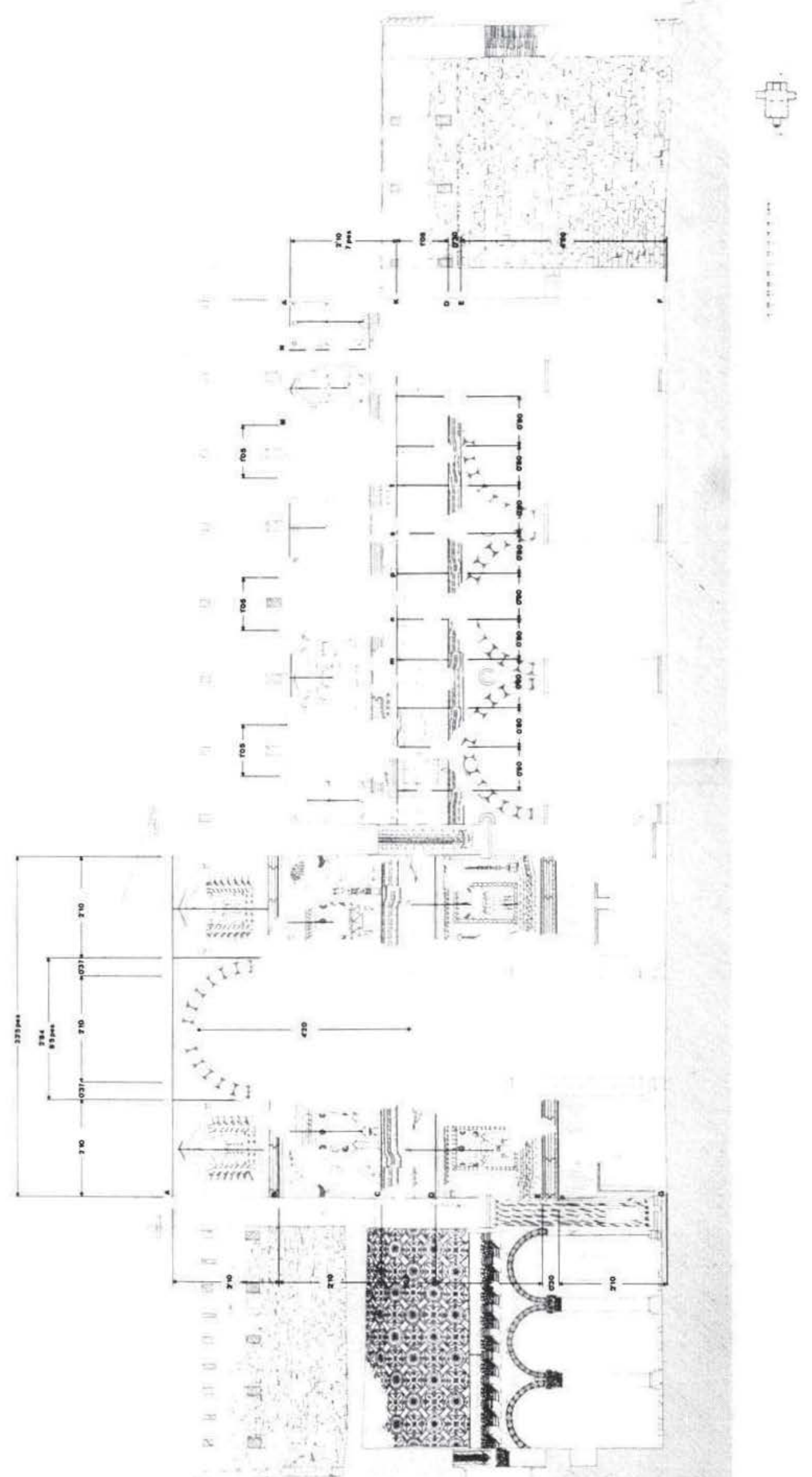




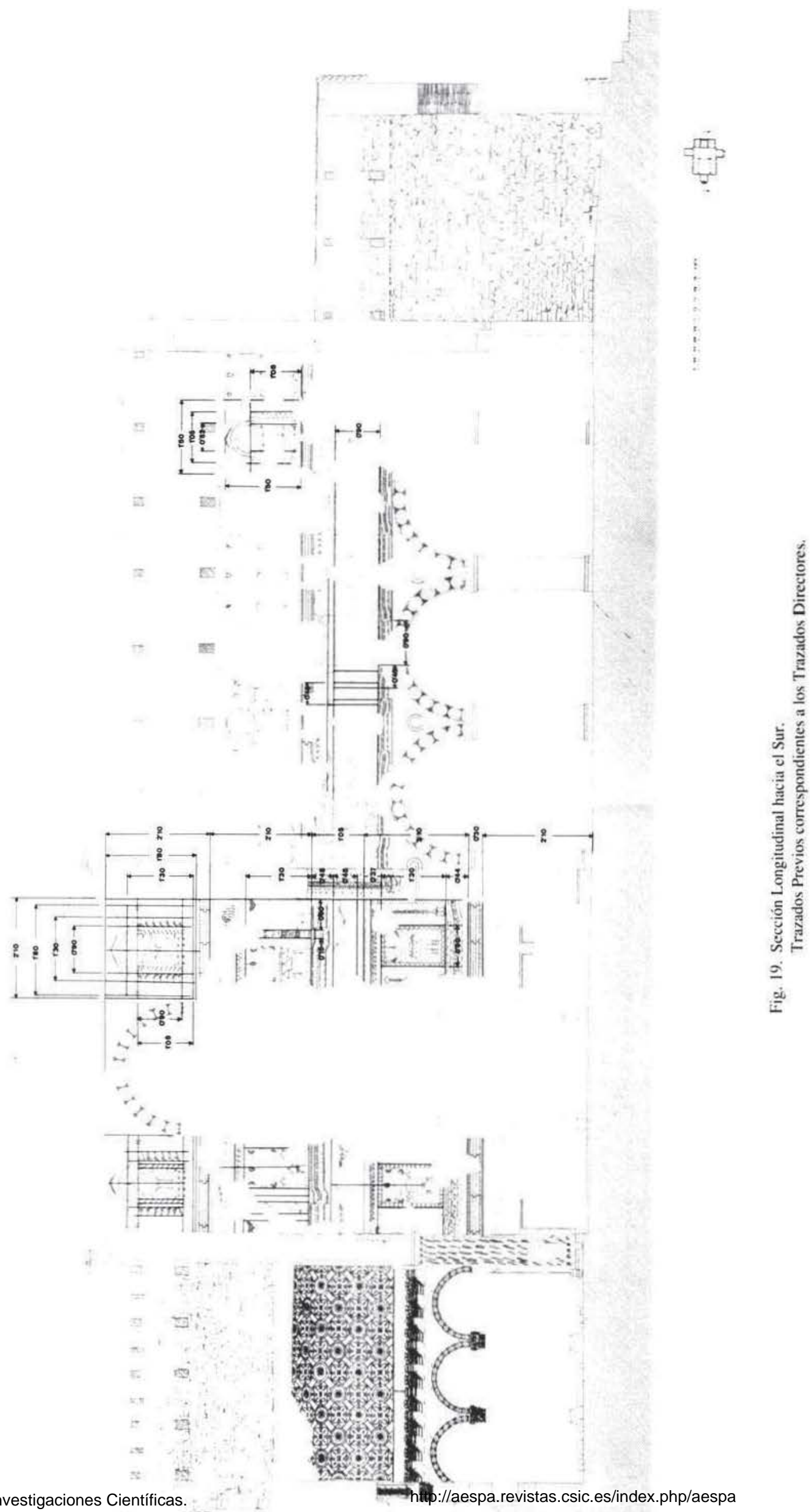




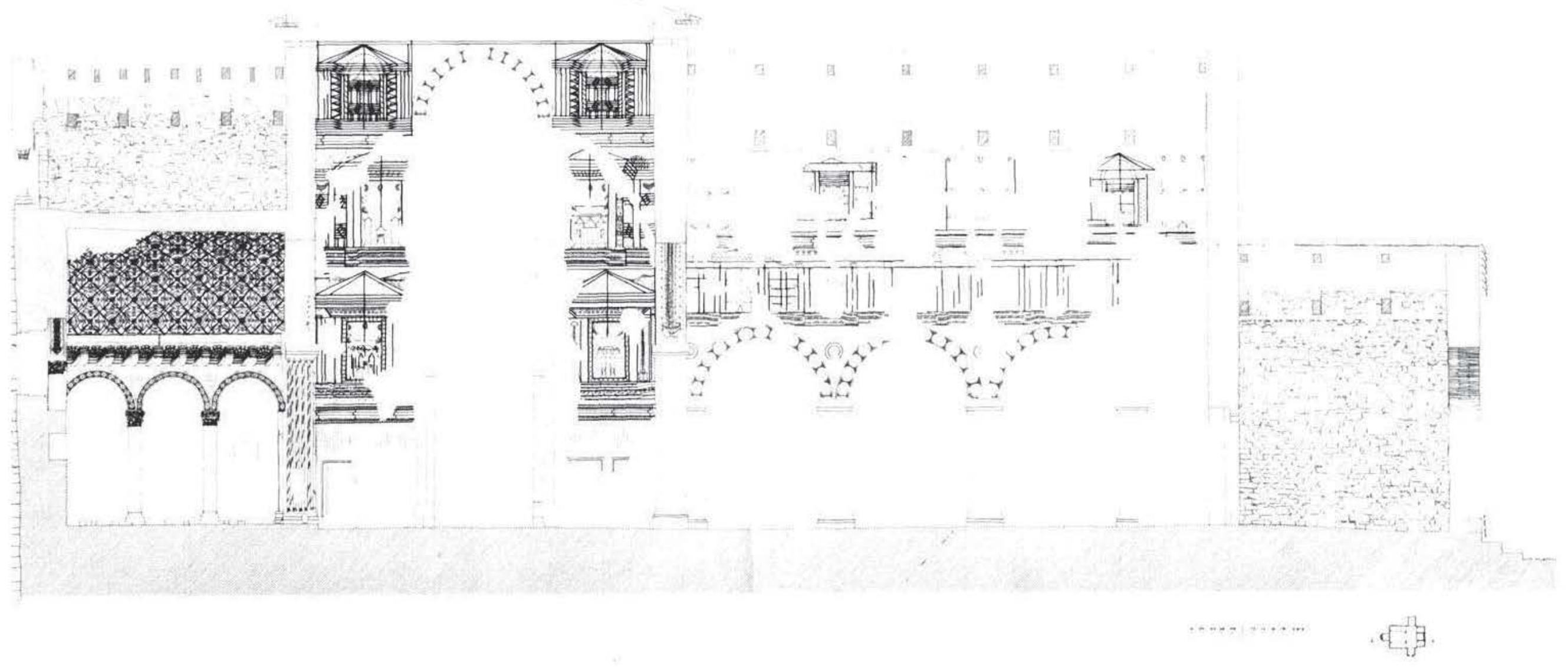

Fig. 20. Sección Longitudinal hacia el Sur.

(c) Consejo Superior de Investigaciones Científicas. 


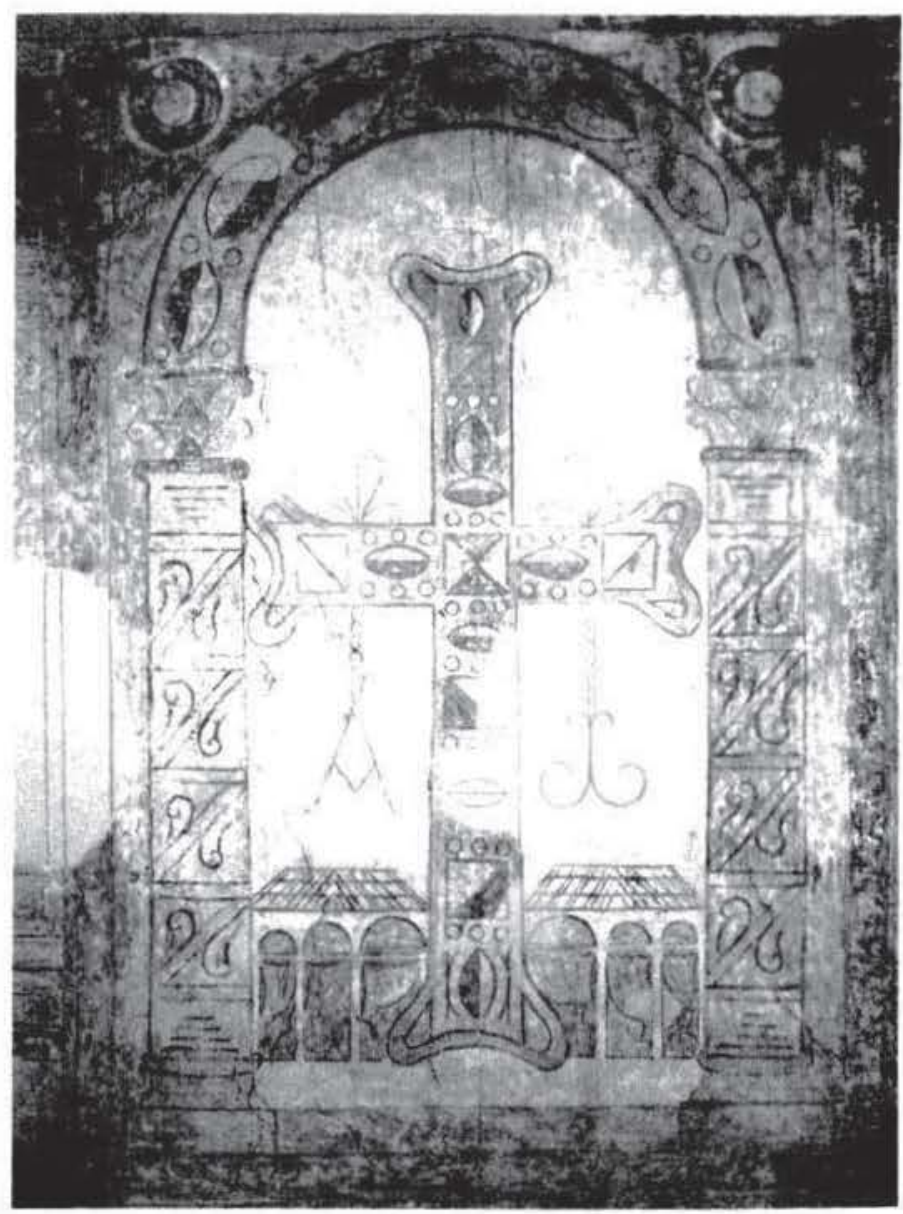

Figura 21.-Cruz de la Anastasis situada en la pared oriental de la Nave Transversal.

sión es variable, tiene $4,10 \mathrm{~m}$. reales, si bien el nivel del suelo no es el original al haber sido sustituido éste por un enlosado de piedra en el transcurso de una restauración efectuada en el siglo pasado. Los $4,20 \mathrm{~m}$. responden a la magnitud real proyectada originalmente como así lo corrobora el traslado de esta medida al nivel de suelo primitivo que aún hoy permanece conservado en una zona próxima al umbral del arco de acceso a la Nave Transversal.

Este nivel se encuentra $10 \mathrm{~cm}$. por debajo del nivel actual de losas de piedra arenisca que recubre actualmente el firme de la iglesia. La medida de $4,20 \mathrm{~m}$. equivale, como ya hemos mencionado, a 14 pes de $0,30 \mathrm{~m}$. La secuencia posterior (figura 19) reserva 1 pes para la altura de la cornisa fingida y 3 pes para el marco arquitectónico de la Zona Central. Distancia que acota la altura del fuste de las columnas, rematadas en capiteles de tradición corintia, que integran la composición del friso de palacios y sobre las cuales descansa un entablamento con su correspondiente frontón. La simetría y proporción introducida se ha articulado de nuevo en torno a la figura del cuadrado, en esta ocasión de 3 pes. Y ello porque, en sentido longitudinal, la medida del intercolumnio de cada Palacio conserva también una dimensión constante de 3 pes. En efec- 


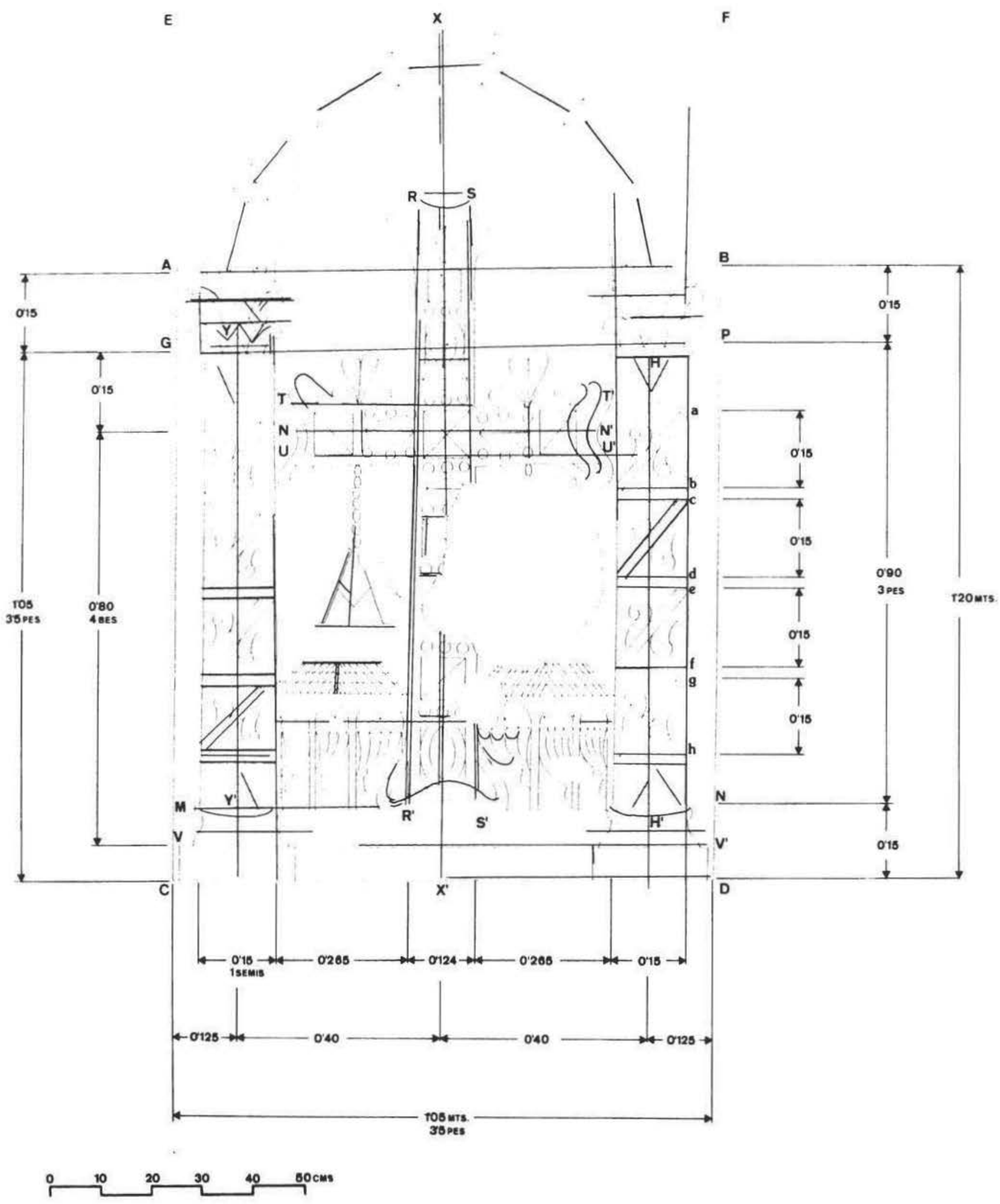

Figura 22.-Detalle del trazado previo de la Cruz. 


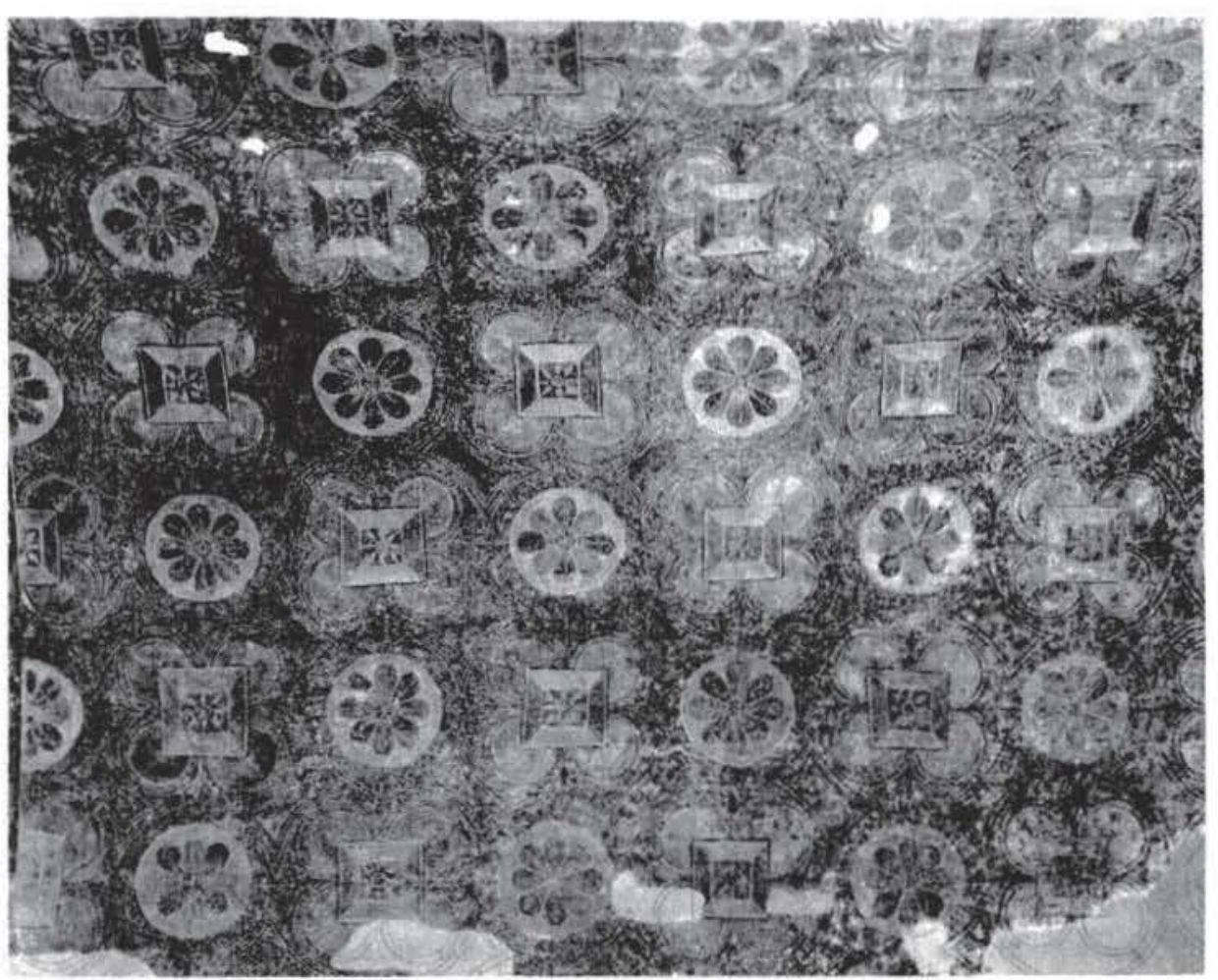

Figura 23.-Composición pictórica de la bóveda del Abside central.

to, estos trazados directores que configuran las líneas maestras de la decoración arquitectónica, se encuentran en directa correspondencia compositiva con los edificios en perspectiva situados entre cada una de las construcciones palaciegas. En la disposición de estos edificios, de 4 bes $(0.80 \mathrm{~m}$.) de ancho (indicada con las letras $\mathrm{m}-\mathrm{n}$ ) incluida la columna de cada uno de los Pala-

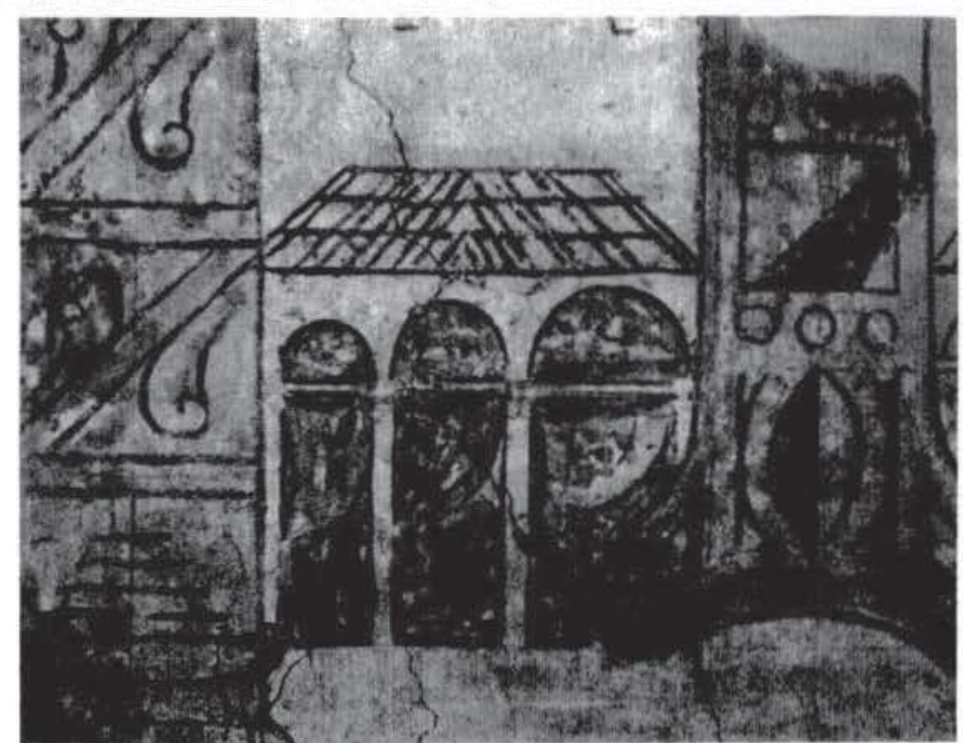

Figura 24.-Detalle de la Cruz de la Anastasis situada en la pared oriental de la Nave Transversal. 


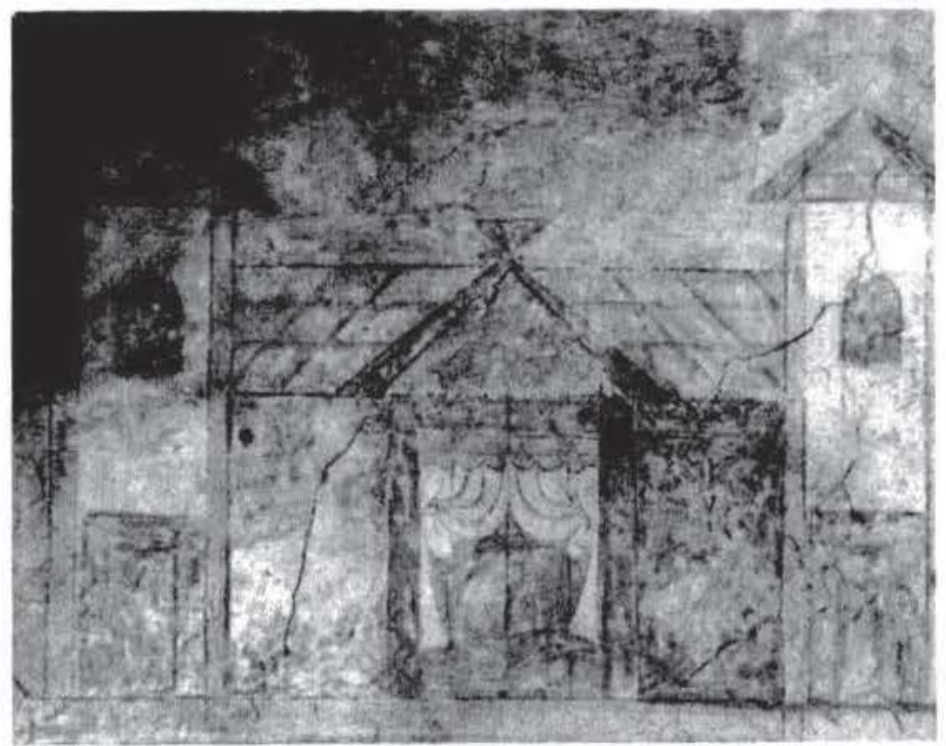

Figura 25.- Pequeño edificio situado en la pared Norte de la Nave Transversal.

cios contiguos, se ha introducido una pilastra centrada interior de $0,10 \mathrm{~m}$. de ancho (tramo d-e) en su fuste. La versatilidad del método ahora empleado se observa en el dimensionado del programa pictórico-arquitectónico: la distancia entre el perfil exterior de la planta y el perfil interior de la columna: p-r ó u-s, es de $0,45 \mathrm{~m}$., es decir, la mitad de $0,90 \mathrm{~m}$. Esta composición del programa, basado en la coordinación modular de un esquema geométrico articulado en torno a dimensiones que contengan un factor de multiplicidad entre sí, facilita de forma decisiva la interpretación y transposición del proyecto y bocetos originales a la superficie final del enlucido. El resto del dimensionado está reflejado en el dibujo: los fustes de las columnas de los Palacios tienen I quincunx $(0,124 \mathrm{~m}$.), y la distancia entre estas columnas y la pilastra interior es de 1 dreans $(0,224 \mathrm{mts})$. Las columnas de los Palacios tienen 1 metro de altura total. El entablamento y el frontón conservan una altura conjunta B-C de 2 bes $(0,40 \mathrm{~m}$.) y el espacio decorado sobre el cual descansa la Zona Superior o de ventanas tiene una altura A-B de 5 pes $(1,50 \mathrm{~m})$. Es de destacar que la altura existente desde el extremo superior de las columnas del friso central hasta el extremo superior del cuadro de la Zona Superior tiene una medida de 7 pes $(2.10 \mathrm{~m}$. $)$.

Estudiaremos en esta Zona Superior el panel configurado por el cuádro M-N-R-S de 1 passus de lado $(1,50 \mathrm{~m}$.) y que contiene una representación palaciega enmarcada por sendas columnas centrales sobre las cuales descansa un arco de medio punto. Observamos que se ha recurrido de nuevo a la figura estable del cuadrado de lado 1 passus, subdividiendo el interior en otro cuadrado de 3,5 pes ( $1,05 \mathrm{~m}$., es decir, la mitad de 7 pes) magnitud relacionada proporcionalmente con el ancho existente entre las columnas interiores y cuya medida es de 3 septunx $(0,525 \mathrm{~m}$.). El arco de medio punto decorado con estrías no está peraltado por lo que conserva el radio de 1,5 septunx. En su interior se encuentra representado el techo cónico de la «tholos». El fuste tiene una anchura de 1 triens $(0,10 \mathrm{~m}$.) y la columna una altura de 3 pes (figura 20).

$\mathrm{El}$ ancho de las tres ventanas existentes es de 3,5 pes, medida significativa del valor que tiene el factor 7 pes escogido como medida modular que dirige todo el esquema compositivo. Como observaremos, este ancho es, a su vez, la mitad del ancho de 7 pes que tiene de dimen- 
sión la ventana abierta en la pared sur de la Nave Transversal. A su vez la altura de la ventana de 1,55 m., está en razón 1,5 con el ancho de 1,05 m. es decir que, 1,55/1,05 =1,5 una relación de carácter pitagórico.

* Respecto al lienzo sur de la Nave Transversal (figura 18), la distribución proporcional vertical introducida en la composición, tiene su fundamento en dividir la altura total en 4 magnitudes de 7 pes $(2,10 \mathrm{~m}$.) más una de 3,5 pes, (la mitad de 7 pes). Iniciando la descripción por la parte inferior tenemos el tramo G-F de 7 pes, que define la superficie del zócalo con decoraciones formadas por bandas de color rojo y negro, alternando con cuadrados y diversas formas geométricas. Una faja cuyo ancho es de 1 pes divide este primer nivel inferior del nivel definido por el primer cuadro de Palacios y cuya altura D-E sigue siendo de 7 pes. Este marco arquitectónico descansa sobre una cornsa fingida ricamente ornamentada cuya altura tiene el valor de $1 \mathrm{cu}$ bitus $(0,44 \mathrm{~m}$.). El ancho tendría la misma magnitud de 7 pes, si bien no se conserva el extremo izquierdo del panel, aunque es perfectamente deducible su magnitud original por la simetría del motivo arquitectónico que contiene el marco. La medida del fuste de la columna, situada en primer plano y a ambos extremos (en la actualidad solamente conservada la correspondiente al sector derecho) tiene una altura de 3,5 palmipes, la misma medida que la correspondiente a los pilares que sostienen un techo con una perspectiva muy acusada, fruto de un punto de fuga que sitúa al observador en un punto muy bajo de la escena representada. El techo está decorado con un motivo de espirales en forma de $\mathrm{S}$ entre los cuales se ha introducido un trifolio. Un detalle del trazado previo de este motivo se puede ver en la figura 11. Entre estos pilares se encuentra un gran vano que enmarca el pequeño edificio central. En realidad se ha representado una columnata en forma rectangular de 3,5 palmipes de alto por 3 pes de ancho, conteniendo pequeñas columnitas con sus respectivas basas y capiteles. Por su parte las columnas extremas tienen una altura de 5 pes $(1,50 \mathrm{~m}$.) con su capitel incluido. En la parte superior del techo descrito se inicia el entablamento, una de cuyas partes mide $1 / 2$ pes $(0,15 \mathrm{~m}$.) y el frontón: 1 cubitus $(0,44$ $\mathrm{m}$.). Le sigue la cornisa fingida policromada con rica ornamentación en cuya línea interior conserva una pequeña decoración de cuadrados divididos diagonalmente y cuyos motivos de representación pudieran ser la imitación de piedras preciosas.

El marco arquitectónico B-C de 7 pes es idéntico igualmente en dimensionado al ya estudiado en la pared occidental de la Nave Transversal. De hecho es una continuación del programa arquitectónico introducido en esta pared. Es importante, por lo tanto, resaltar que ha sido ajustado todo el proyecto mural al dimensionado de los paramentos. De tal suerte que, como se puede observar, el ajuste de 7 pes introducido entre las columnas de la pared occidental de la Nave Transversal tiene su perfecta y lógica continuidad en las paredes laterales Sur (aquí estudiada) y Norte y Este.

El último tramo A-B, perteneciente a la Zona Superior o de ventanas, respeta la distribución jerárquica geométrico-proporcional de 7 pes de alto (figura 19). El marco arquitectónico pertenece al mismo estilo que el estudiado en el lienzo sur de la Nave Central. Está configurado por un cuadrado H-A-N-B de 7 pes de lado, medida que se repetirá tripartitamente en la distribución vertical de la Pared Sur como estudiaremos más adelante. En la parte inferior está representada una franja a modo de zócalo sobre la cual descansa el panel. La distancia A-R de 6 pes $(1,80 \mathrm{~m}$.) forma cuadrado con la A'-H', cuya magnitud define la medida entre las columnas exteriores, siendo la altura total de la columna de 3,5 deunx $(0,96 \mathrm{~m}$.). La figura del cuadrado está igualmente presente en la subdivisión posterior (figura 18). Así, la altura a-c y b-d, de 3,5 palmipes 
$(1,30 \mathrm{~m}$.) es el lado de un cuadrado en el que su otro lado es la distancia a-b y c-d existente entre los triángulos representados en los intercolumnios laterales y ornamentados por dibujos que representan motivos florales. El ancho del intercolumnio interior sobre el cual apoya el arco de medio punto tiene una medida de 4 hes $(0,80 \mathrm{~m}$.), mientras que la altura de la columna es de 3 pes, formando un cuadrado e-f-g-h. Las medidas interiores se reparten así: el ancho del fuste de la columna interior sogueada tiene 1 palmus $(0,075 \mathrm{~m}$.) y las pilastras adosadas del piso alto $0,06 \mathrm{~m}$. Las del piso inferior 1 sescuncia $(0,0373 \mathrm{~m}$.). A su vez, el ancho del intercolulumnio central del piso alto $(\mathrm{m}-\mathrm{n})$ tiene 1 pes $(0,30 \mathrm{~m}$.) y la altura de la columna 3,5 pes $(0,70 \mathrm{~m})$. Las columnas inferiores tienen una altura de 1 semis $(0,15 \mathrm{~m}$.) y un ancho del fuste de 1 sescuncia..

Por lo que al sector izquierdo del lienzo corresponde, éste mantiene la misma semejanza metrológica y de esquemas de composición que el sector derecho ahora analizado. Así, nos encontramos con dos secuencias de paneles arquitectónicos verticalmente distribuidas de acuerdo a unas reglas de dimensionado basada en la magnitud de 7 pes. Medida que seguirá manteniendo ahora una relevancia muy importante. Los dos sectores de revestimiento pictórico están separados por un ventanal rematado en un arco de medio punto cuya arquivolta contiene dibujos de círculos negros y rojos entre los cuales se han intercalado haces de hojas contrapuestas. El ancho interior de este ventanal tiene una medida de 7 pes para el lienzo sur (semejante metrológicamente al lienzo Norte). El ancho o profundidad de la arquivolta es de 1 palmipes $(0,37 \mathrm{~m}$.) lo que nos ofrece una dimensión total interior entre los dos marcos o paneles arquitectónicos izquierdo y derecho de 9,5 pes $(2,84 \mathrm{~m}$.) y una medida total de la pared de 23,5 pes, exactamente la mitad de la longitud total de la Nave Transversal. A destacar esta identidad que se ha tenido presente, por parte del maestro medieval, de equilibrar y ajustar al programa pictórico mural el dimensionado del ventanal con el de los paneles, ajustando todos ellos a un esquema modular en el que se integran de una forma perfectamente proporcional. El ventanal, por su parte, tiene una altura de 14 pes $(4,20 \mathrm{~m}$.) configurando un doble cuadrado. Descontando el radio del arco de medio punto de $1,05 \mathrm{~m}$. nos queda una altura de la jamba de $3,15 \mathrm{~m}$. encontrándose en relación 1,5 con el radio: $3,15 / 2,10=1,5$. La misma relación que habíamos observado en los ventanales de la Nave Central.

* El tercer conjunto pictórico importante lo constituye la bóveda del Abside Central (figuras 20 y 23). La composición de trazados previos está integrada por una cuadrícula o retícula modular con $45^{\circ}$ de inclinación y una separación entre sus ejes de simetría de 1 pes $(0,30 \mathrm{~m}$.) Estos ejes marcan la posición de los puntos de intersección de la malla, situando espacialmente el centro donde deben inscribirse lo centros de las circunferencias y cuadrados que configuran la composición decorativa de la bóveda.

\section{ANÁLISIS DEL TRAZADO PREVIO DE LA CRUZ BAJO EL ARCO}

La Cruz de la Anastasis o Vera Cruz (figuras 21, 22 y 24), como ya hemos hecho mención líneas arriba, destaca de forma especial en el centro simétrico de la Zona Superior de cada uno de los lienzos transversales de la Iglesia: Nave Transversal y Nave Central. Hoy solamente se conservan en buen estado, de las cuatro cruces originariamente existentes, la situada en la pared occidental de la Nave Central y la de la pared oriental de la Nave Transversal. Esta última es la que será objeto del análisis metrológico y de composición, pues consideramos que es la 


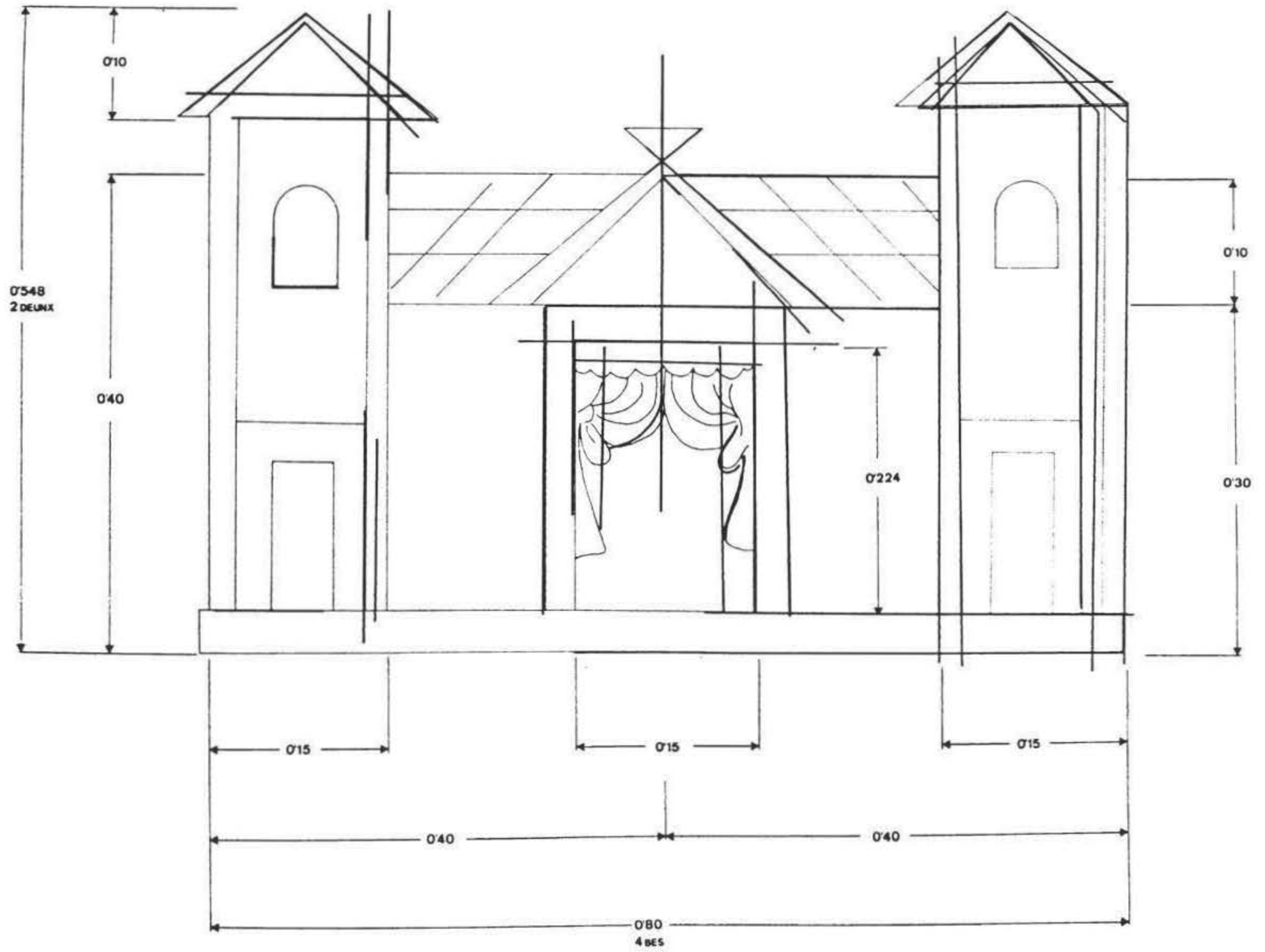

Figuras 26 y 26 bis. - Trazado previo de pequeño edificio situado en la pared Norte de la Nave Transversal. 
que se encuentra en mejor estado de conservación, facilitando con ello un estudio más preciso. Su ubicación real se puede ver en la figura 21 .

Los trazados previos que permanecen perfectamente visibles en su superficie están reflejados en la figura 10. El surco de algunas líneas incisas ha desaparecido pero en su mayoría se conserva aún la huella, lo cual permite reconstruir el proceso original de distribución y composición de las medidas y proporciones introducidas.

El campo rectangular que enmarca el arco apoyado sobre dos columnas, y en el interior del cual se ha representado la cruz latina, tiene unas medidas muy significativas. Su ancho C-D es una magnitud con un valor de 3,5 pes $(1,05 \mathrm{~m}$.) El doble de este valor, como ya hemos estudiado, representa la medida básica de regulación modular en la composición de la pintura mural. En el interior de este ancho de 3,5 pes se han grabado las líneas de la composición de acuerdo a una regulación de intervalos definidos inicialmente por el pes de $0,30 \mathrm{~m}$. En efecto, el arco está asentado sobre dos columnas cuyo ancho es de 1 semis, $1 / 2$ pes $(0,15 \mathrm{~m}$.) cada una. Cada columna conserva, a su vez, un eje de simetría central: $\mathrm{Y}^{-\mathrm{Y}^{\prime}}$ y $\mathrm{H}-\mathrm{H}^{\prime}$, siendo su distancia al eje de simetría central X-X' de 2 bes $(0,40 \mathrm{~m}$.). La subdivisión proporcional posterior se centrará en torno a estas pautas metrológicas. Así, la altura de la columna ha sido fijada por medio de 4 ejes directores incisos en el enlucido. Son estos el A-B y el G-P separados entre sí $1 / 2$ pes y que delimitan la altura del capitel de tradición corintia, y el M-N y el C-D de igual magnitud: $1 / 2$ pes $(0,15 \mathrm{~m}$.), que definen la altura de la basa. Las columnas, a su vez, están divididas en varios sectores decorados con motivos curvilíneos y trazados esquemáticos en diagonal. Estas franjas conservan entre sí surcos de trazado previo y una equidistancia significativa entre ellos: 1/2 pes, (a-b; c-d; e-f; g-h). La altura de la columna tiene así una medida de 4 pes $(1,20 \mathrm{~m}$.) y el fuste 3 pes $(0,90 \mathrm{~m}$.). Por lo que al arco se refiere, está adornado con óvalos apuntados imitando piedras preciosas, en las que se ha registrado el trazado de sus ejes, conserva un espesor igualmente de $1 / 2$ pes y sus radios, tanto interior como exterior, están en dependencia del ancho intercolumnar ya descrito. Se conserva aún la huella del centro de la punta del compás.

La cruz, propiamente, no tiene pie (está representada como sí permaneciese en el aire) y sus brazos están rematados en formas redondeadas lobuladas. Se percibe perfectamente en sus cuatro extremos la huella de un trazado previo anterior rectificado con posterioridad y que es el que permanece en la actualidad. Conserva dos ejes de simetría; uno ya descrito: el vertical X$\mathrm{X}^{\prime}$, eje que divide en dos partes iguales la basa de cada columna. 4 bes es, como hemos visto, la distancia entre los ejes correspondientes de cada columna. La medida del ancho de los brazos de la cruz es de 1 quincux $(0,125 \mathrm{~m}$.) y están definidos sus perfiles por trazados incisos que hemos marcado con las letras R-R' y S-S' para los perfiles verticales y T-T' y U-U' para los horizontales. El decorado interno del cuerpo de la cruz está configurado por dibujos de cuadrados, pequeños círculos y óvalos en referencia directa a imitaciones de piedras preciosas, pedrería y perlas, no conservándose las líneas incisas previas de la misma.

Respecto a los dos edificios situados a los pies de la cruz tienen un arco de acceso de medio punto y dos huecos contiguos. Configuran una arquería con disminución progresiva de sus diámetros simulando una perspectiva, pero mantienen el nivel de ejes constante. La distancia hasta el hueco de entrada es de 1 semis $(0,15 \mathrm{~m}$.), las subdivisiones posteriores de la arquería son aleatorias pero con la evidente intención de introducir un claro efecto de perspectiva. La altura desde la base al eje de la arquería es de 1 septunx $(0,174 \mathrm{~m}$.) aproximadamente. De los tres huecos, el mayor puede ser considerado como puerta de acceso y los otros dos como constitutivos 

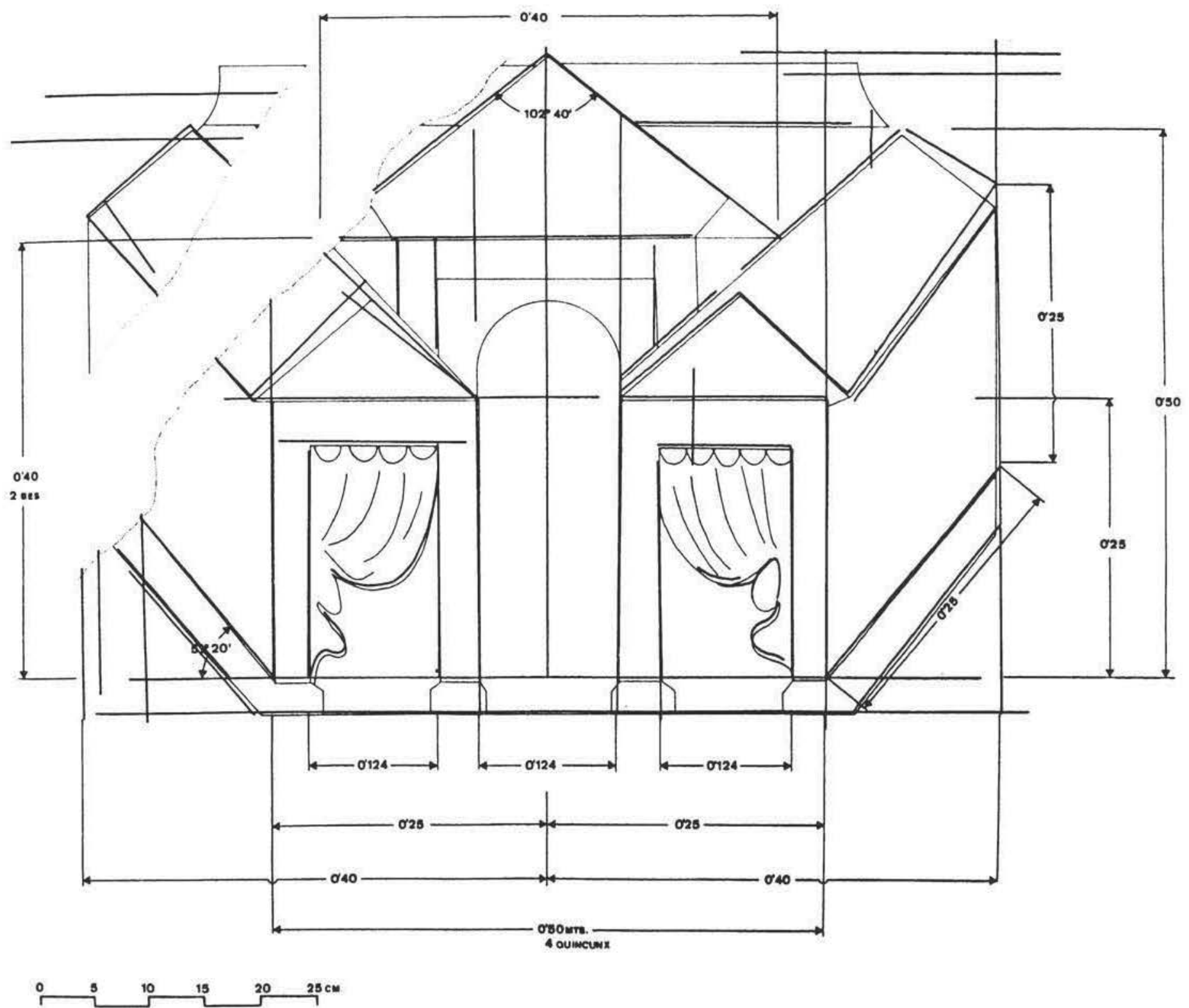

Figuras 27 y 27 bis.-Trazado previo de pequeño edificio situado en la pared oriental de la Nave Transversal. 


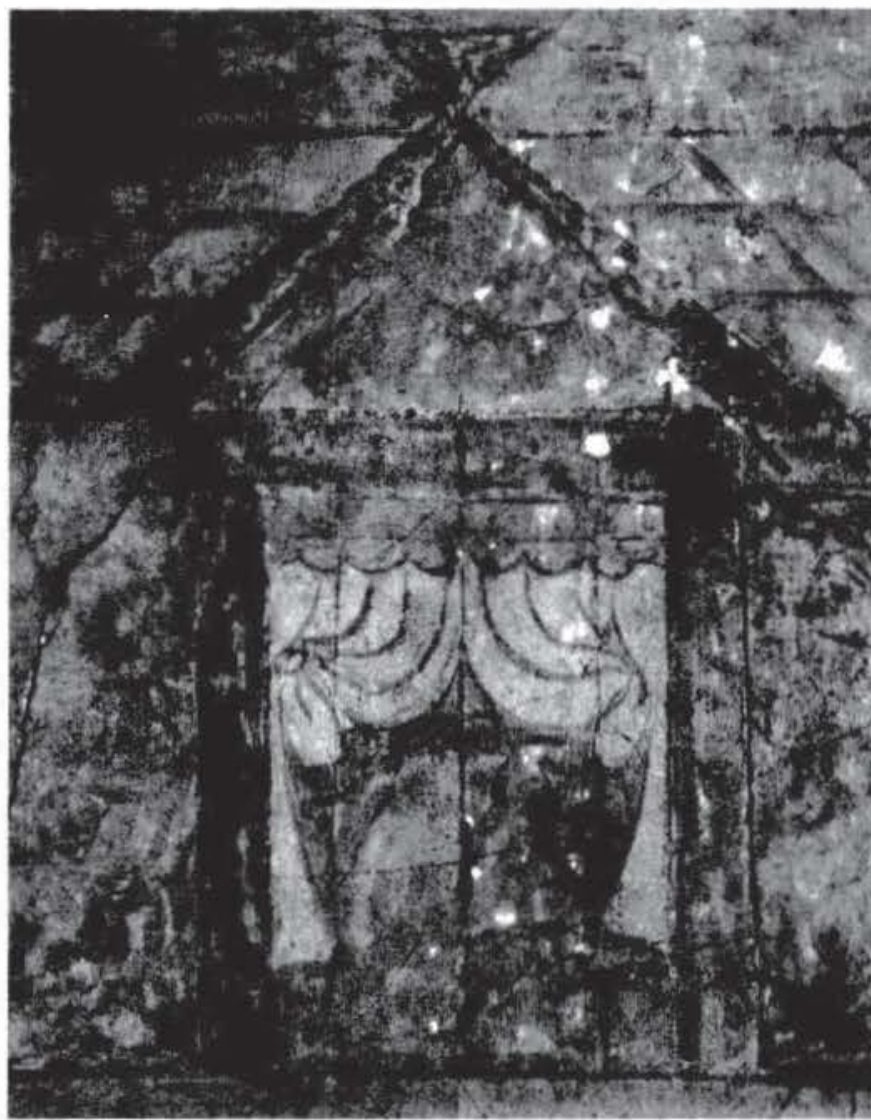

Figura 28. - Detalle de la puerta central del edificio situado en la pared Norte de la Nave Transversal.

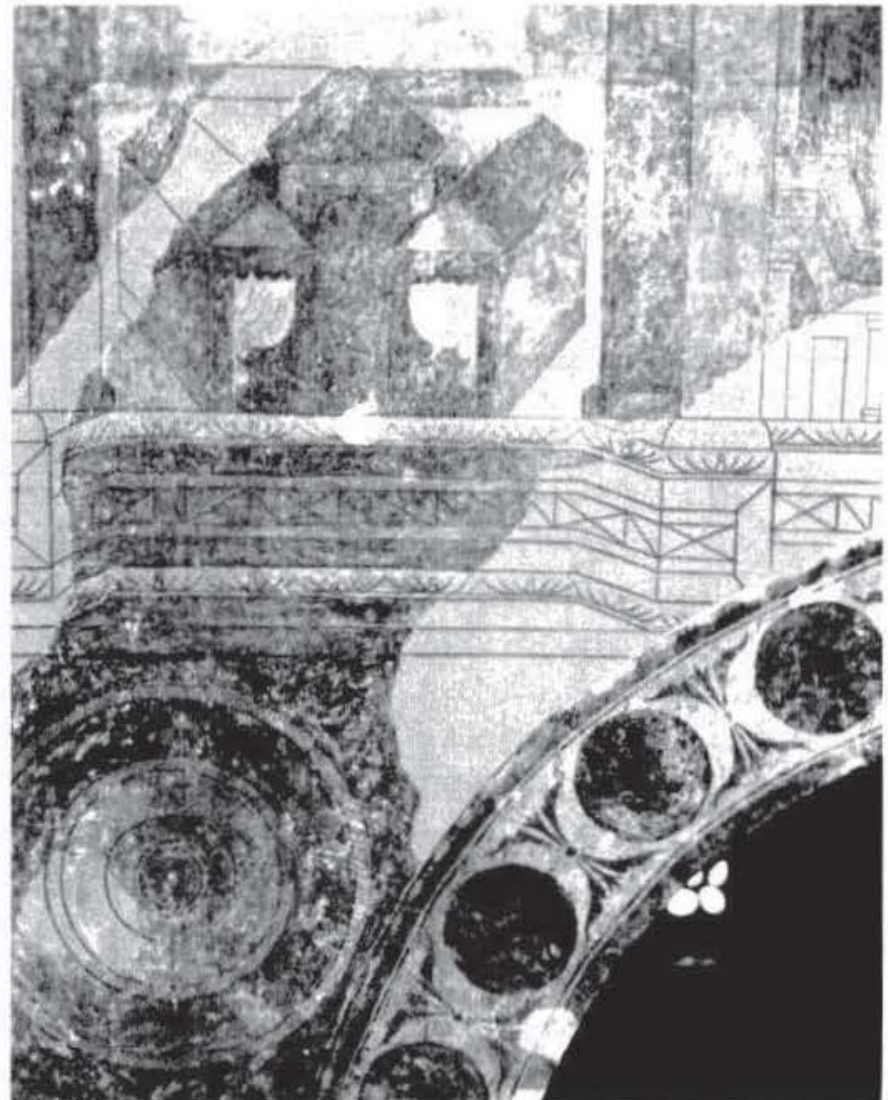

Figura 29.-Edificio situado en la pared oriental de la Nave Transversal.

de la arquería interior, pendiendo de los tres huecos cortinajes recogidos hacia un lateral. Se conserva aún la huella de los centros de trazado del compás para construir los arcos de medio punto de la arquería y en el edificio izquierdo permanecen igualmente los trazados de incisión de los límites horizontales del tejado a dos vertientes en un efecto de perspectiva central que se encuentra en desarmonía con la perspectiva introducida para el trazado de la arquería. La altura hasta el tejado es de 1 dodrans $(0,2245 \mathrm{~m}$.) y la altura propia del tejado 1 triens $(0,10 \mathrm{~m}$.).

\section{ANÁLISIS DE LOS PEQUEÑOS EDIFICIOS: TRAZADO PREVIO Y CRITERIOS GEOMÉTRICOS DE PROPORCIÓN Y COMPOSICIÓN}

De los cerca de doce modelos diferentes en su estilo que se encuentran en las iglesias representadas en las pinturas de Santullano, hemos escogido seis modelos que reflejan de forma fiel la técnica y los procedimientos geométricos empleados en el trazado de estas pequeñas edificaciones. Su repetición por pares y en algunos casos en posición invertida, representa una circunstancia que contribuye a resumir y exponer sucintamente las diversas fórmulas geométricas y de proporción empleadas. Por otra parte, en la actualidad no se conservan todas 

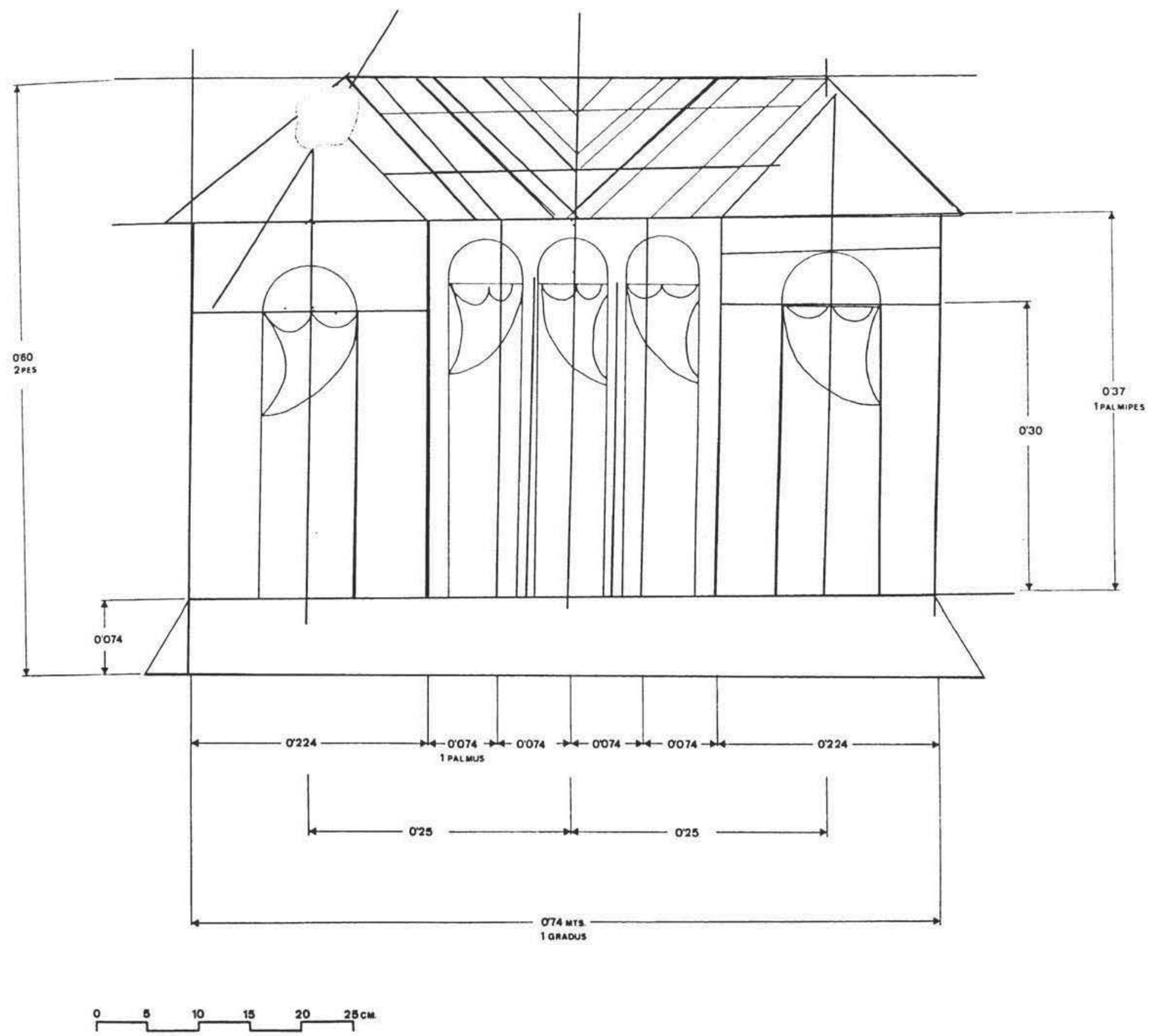

Figura 30 y 30 bis.-Trazado previo de pequeño edificio situado en la pared occidental de la Nave Transversal. 
las edificaciones pintadas. De los 38 edificios originarios, hoy solamente se conservan 24 y de ellos varios muy deteriorados. Algunos, a su vez, no conservan trazados previos y en algunos casos el recurso al empleo de trazados ha sido tan limitado que su análisis no supone avance cualitativo importante.

La selección efectuada pretende, pues, analizar el diseño proyectual empleado en aquellos edificios que podemos considerar como prototípicos en el uso de determinados procedimientos geométrico-proporcionales y de composición comunes a la práctica de los maestros medievales asturianos.

Figura 26.-Edificio situado en el lienzo Norte de la Nave Transversal, a la derecha de la pared (figuras 25 y 28$)$. Se trata de un edificio de 4 bes $(0,80 \mathrm{~m}$.) de largo, por 2 deunx $(0,54 \mathrm{~m}$.) de altura. Está flanqueado por dos torres con tejado a dos aguas de 1 semis $(0,15 \mathrm{~m}$.) de ancho. En la fachada la altura desde el suelo al tejado a dos vertientes es de 2 bes también, la mitad del largo total. El muro del edificio tiene una altura de 1 pes. Su altura es de 1 dodrans $(0,224 \mathrm{~m}$.). La libertad del pintor de este edificio ha introducido variaciones en el esquema inicial de composición. Sobre la marcha ha alterado la trayectoria de algunas líneas originales, e introducido otras cuya aleatoridad es evidente. En otros casos ha ido improvisando simultáneamente al propio proceso de ejecución pictórica del motivo. Así, ha dibujado un doble perfil a las torres laterales rematándolas con un tejado de doble línea en ángulo de $102^{\circ}$. El repertorio de improvisación y reelaboración sobre la marcha es evidente, e incluía también el frontón con doble línea repetida a igual ángulo de $102^{\circ}$ así como las puertas rectangulares de las torres. La puerta central conserva ciertas huellas de incisiones previas de los pliegues de los cortinajes que se recogen a ambos lados de las jambas, así como el surco del trazado, grabado en semicírculo, de los enganches de las cortinas. A su vez el tejado conserva también incisiones que imitan un tipo de teja ancha de imprecisa identificación ¿tegula romana?. Todo el edificio se sustenta sobre un zócalo corrido.

Figura 27.-Edificio situado en el lienzo oriental de la Nave Transversal (figuras 21 y 29), en el sector izquierdo de la pared. Conserva un cuerpo central de forma rectángular rematado en un frontón con cubierta a dos aguas y un ángulo de inclinación de $51^{\circ} 20^{\circ}$. A sus lados se abren dos naves laterales con apertura en cada frente del edificio de una puerta de acceso con cortinajes recogidos hacia un lateral. La pared de cada nave extrema está representada en perspectiva, conservando sus líneas de fuga la misma inclinación de $51^{\circ} 20^{\prime}$, la misma que el frontón central. El pintor del edificio se ha regido por unas efectivas reglas de representación perspectiva. Reglas simples cuya base de configuración geométrica se inicia haciendo coincidir metrológicamente la altura de los edificios laterales de 4 quincunx $(0,50 \mathrm{~m}$.) con el ancho de la fachada de 4 quincunx también. La altura de la fachada conserva igual medida proporcional de 2 quincunx, tanto en lo que respecta al primer plano de fachada como al plano de fondo de la perspectiva: 2 quincunx. Incluso la longitud del fondo lineal del edificio (no su proyección), es de 4 quincunx. El resto de magnitudes introducidas se ha establecido igualmente de acuerdo a un reparto simple proporcional. Así, el ancho de las puertas es de aproximadamente 1 quincunx $(0,125 \mathrm{~m}$.) conservando unos cortinajes en los que se ha pregrabado con incisiones gran parte de su trazado pictórico final. La altura total del edificio, incluida la construcción con una puerta central y frontón con inclinación a dos vertientes en ángulo de $51^{\circ} 20^{\prime}$, es de 2 pes $(0,60 \mathrm{~m}$.) y el ancho total 4 bes $(0,80 \mathrm{~m}$.). Considerar finalmente que el conjunto arquitectónico se cierra por el fondo con un muro que presumiblemente pretende demarcar el límite de un patio cerra- 


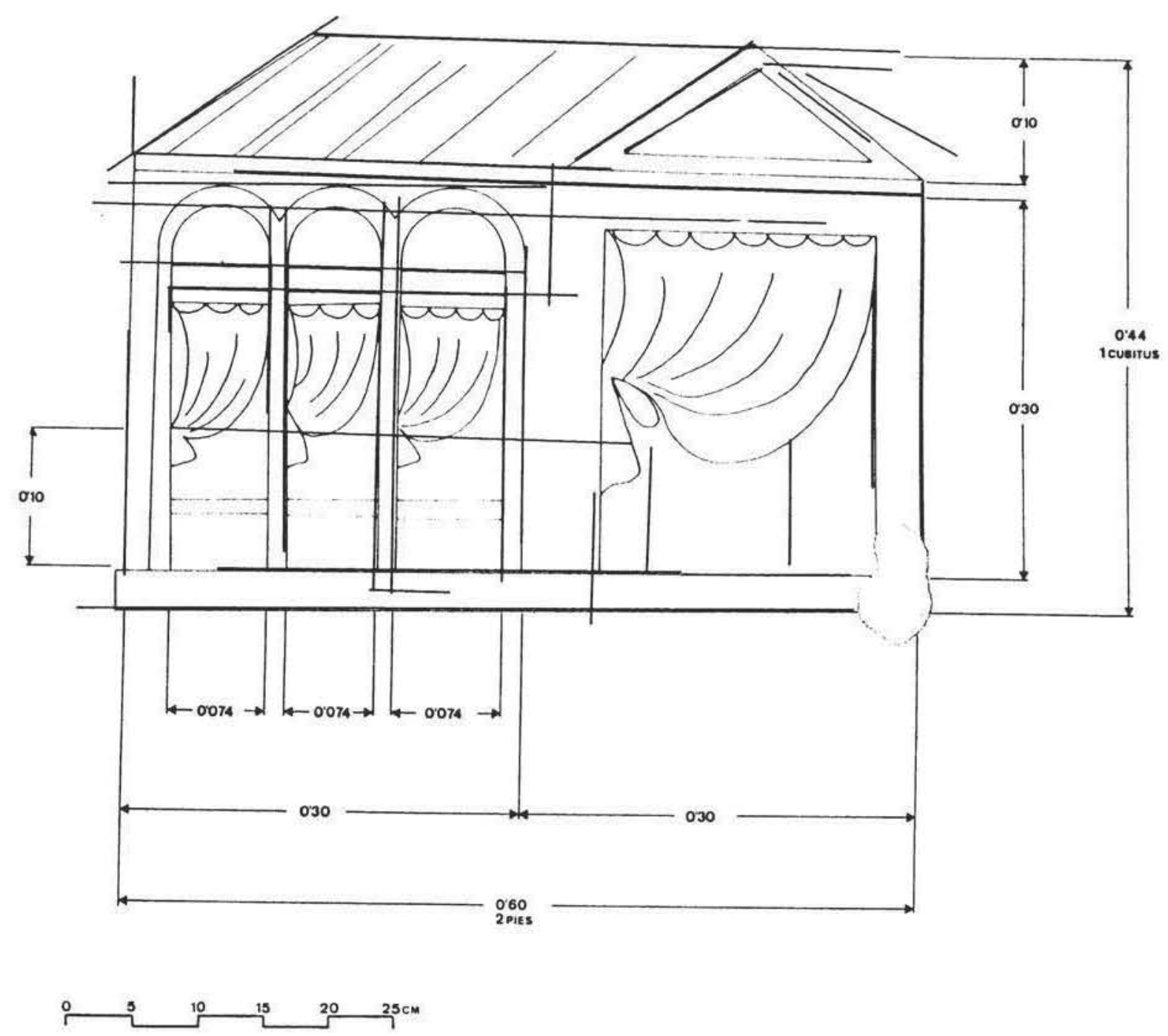

Figura 31 y 31 bis.-Trazado previo de pequeño edificio situado en la pared Norte de la Nave Transversal. 
do interior. El tejado de las edificaciones laterales no conserva la representación de tejas que supuestamente tendría; su efecto de perspectiva ha sido ejecutado de forma intuitiva, en un intento de aproximación a una representación ilusionista de lejanía.

Figura 30.-El edificio que estudiaremos ahora está situado en la pared occidental de la Nave Transversal (figura 9) en el lado izquierdo del lienzo. Las dimensiones generales del mismo son de 1 gradus de longitud, es decir, 2 palmipes $(0,74 \mathrm{~m}$.) por 2 pes de altura total $(0,60$ $\mathrm{m}$.). La altura estricta de la fachada exenta de zócalo y tejado es de 1 palmipes $(0,37 \mathrm{~m}$.). Es decir, que la fachada ha sido construida de acuerdo a la figura geométrica de un doble cuadrado. El edificio conserva una perspectiva central acusada por la dirección del tejado a dos vertientes. La orientación de las tejas convergen en un eje central que descubre dos naves laterales con un ancho de fachada de aproximadamente 1 dodrans $(0,224 \mathrm{~m}$.). Los ejes centrales de las fachadas están separados 2 quincunx $(0,25 \mathrm{~m}$.) cada uno, y los huecos de las puertas de acceso tienen un ancho de 1 triens $(0,10 \mathrm{~m}$.) excepción hecha de los tres arcos elevados del interior cuyo ancho es de 1 palmus cada uno $(0,74 \mathrm{~m}$.). Observar que se ha dividido en tres ejes el espacio central con una separación aproximada entre ellos de 1 palmus, habiéndose corregido con posterioridad dicho trazado regulador por evidentes motivos de simetría. Los cortinajes han sido trazados sin recurrir al grabado previo, sí en cambio, las tejas en las que se conservan surcos de la orientación inicial introducida. El zócalo sobre el cual descansa todo el edificio mide también 1 palmus.

Figura 31.-Edificio situado en la Pared Norte de la Nave Central, en el lado izquierdo del lienzo. Las dimensiones generales del mismo son de 2 pes de largo $(0,60 \mathrm{~m}$.) y 1 cubitus de alto $(0,44 \mathrm{~m}$.). Al igual que las edificaciones estudiadas es una construcción con una fachada principal rematada en frontón con tejado a dos vertientes. En la fachada lateral se abren tres ventanas con arcos de medio punto levantados sobre un estrecho zócalo. Tanto la puerta de acceso como los huecos de ventana tienen travesaños a modo de barras de los cuales cuelgan sendos cortinajes recogidos hacia un lateral. Metrológicamente la fachada tiene 1 pes de altura y el tejado $0,10 \mathrm{mts}$. Igual medida de 1 pes conservan en longitud los tres ventanales. Cada uno tiene 1 palmus de ancho. Se han iniciado estas pinturas partiendo de un trazado inciso de los ejes regulares; sobre estos se situarían los centros de los arcos de medio punto, así como las líneas directrices de los enmarques de cada ventanal. Es de suponer que el resto de las líneas hayan sido trazadas en el transcurso del proceso de ejecución.

Figura 32.-Construcción situada en la pared occidental de la Nave Transversal (ver plano general en la figura 9), en el lado izquierdo del lienzo. Es un edificio de dos plantas con una clara representación de sillares trabajados en sus paramentos. Conserva dos fachadas con dos puertas de acceso rematadas por sendos frontones. Tiene tejado a dos vertientes con una representación de perspectiva central. Las tejas han sido dibujadas con una identificación presumiblemente de tradición romana. Geométricamente ha sido diseñado con cuidada proporción. La fachada de la planta baja mide 2 palmipes y la altura total de la misma, con tejado incluido, 1 palmipes. La fachada, por su parte, mide 1 deunx $(0,27 \mathrm{~m}$.). El ancho de la puerta baja y el tramo recto de fachada miden, a su vez, $1 / 2$ pes $(0,15 \mathrm{~m}$.) respectivamente. Su altura es de 0,224 $\mathrm{m}$. Respecto al piso superior su altura es de 1 bes $(0,20 \mathrm{~m}$.) y el ancho de la fachada 2 deunx $(0,548) \mathrm{m}$.

Figura 33.-Constituye una de las grandes edificaciones pictóricas. Está situada en la pared occidental de la Nave Central, a la derecha del lienzo. La construcción reproduce una iglesia, 


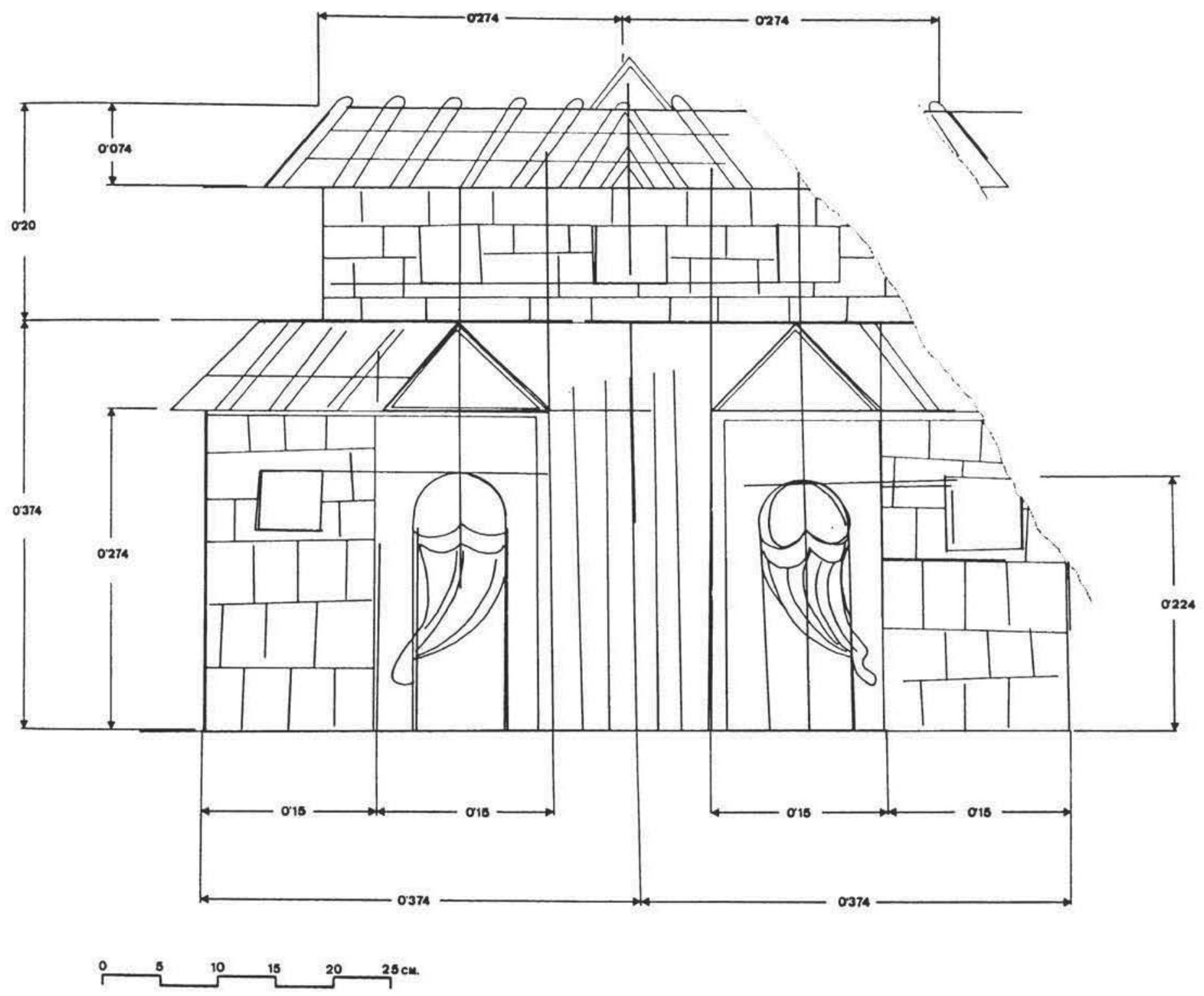

Figura 32 y 32 bis.-Trazado previo de pequeño edificio situado en la pared occidental de la Nave Transversal. 


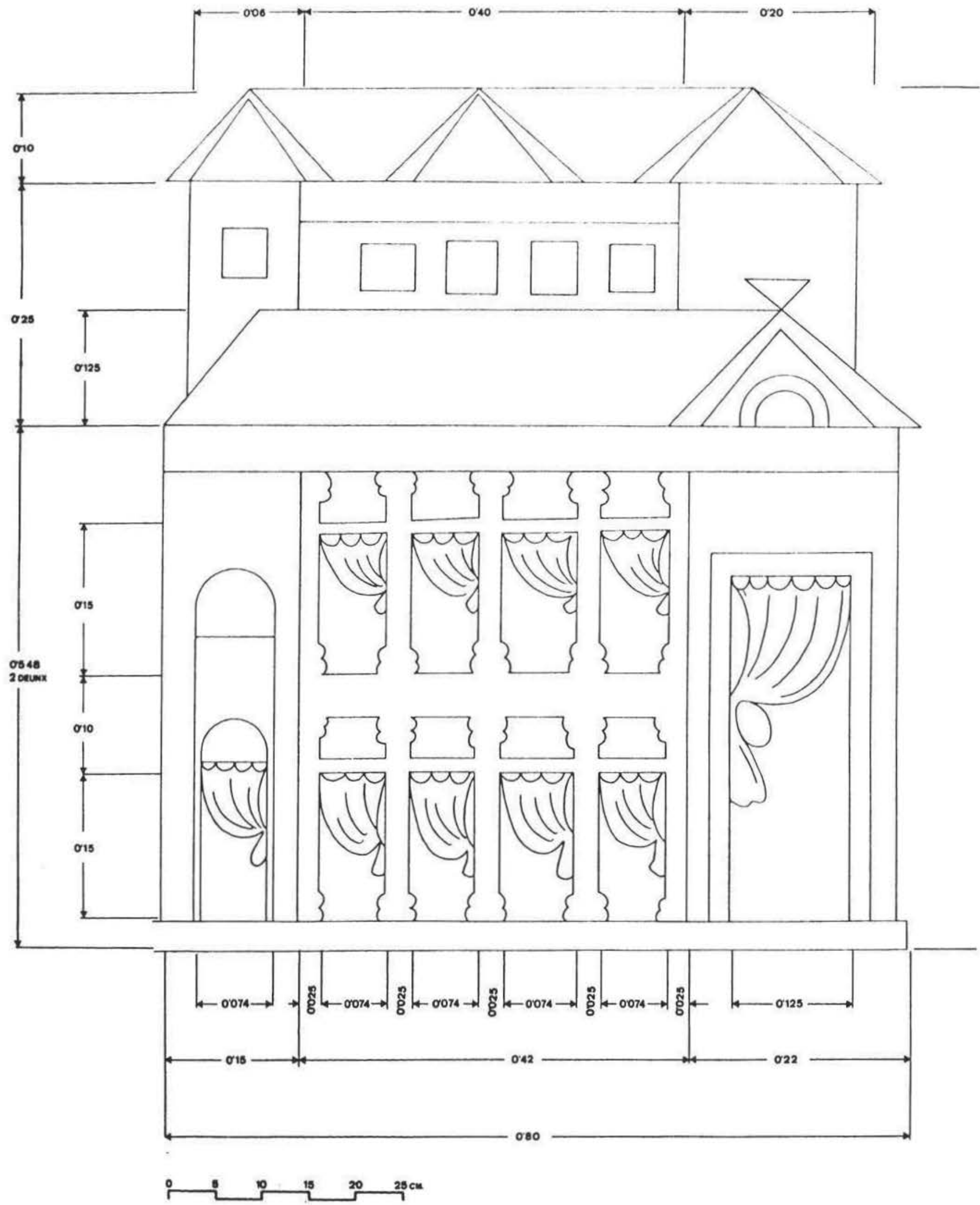

Figura 33 y 33 bis.-Trazado previo de uno de los grandes edificios situados en la pared occidental de la Nave Central. 
representando en un mismo plano la visión del exterior e interior de la misma. Respecto a la sección interna; una vista de las dos plantas interiores separadas por columnas y en las que en sus huecos, y sujetas por anillas a unas barras, cuelgan cortinajes. A la izquierda del edificio nos encontramos con una gran puerta con arco de medio punto, de la cual pende un cortinaje recogido hacia un lateral. A la derecha, una puerta rectangular con otro cortinaje recogido hacia la izquierda, encima del cual se encuentra un frontón con dos semicírculos. Estas serían las vistas exteriores del edificio y sus previsibles entradas al recinto sagrado. El resto de edificaciones que se elevan por encima del tejado tienen dificultades de interpretación sobre su función. En torno a un cuerpo central con cuatro ventanas se adosan dos torres laterales rematadas por un frontón cada una, la fachada central conserva tejado a dos vertientes y detrás de ella se levanta otro frontón a modo de una nueva representación de otro edificio más lejano. Metrológicamente tiene un ancho total de aproximadamente 4 bes $(0,80 \mathrm{~m}$.) y una altura de 3 pes $(0,90 \mathrm{~m}$.). El cuerpo central dividido en dos plantas tiene una división geométrica regular cuyas medidas entre columnas son de 1 palmus $(0,074 \mathrm{~m}$.) y cuyo ancho de columna es de 1 uncia $(0,024 \mathrm{~m}$.). La altura del hueco de cada planta es de $1 / 2$ pes. Respecto a las vistas exteriores, el cuerpo derecho de la construcción conserva un ancho de 1 dodrans y la puerta tiene 1 quincunx $(0,125 \mathrm{~m}$.) de ancho a su vez. La Fachada Principal tiene una altura de 2 deunx $(0,548 \mathrm{~m}$.), mientras que el conjunto de tejado y fachada superior del edificio superior es de 2 quincunx, siendo la longitud de esta fachada de 2 bes y su altura $0,10 \mathrm{~m}$. Como se puede observar el dimensionado de todo el conjunto se establece en torno a medidas que son múltiplos entre sí y se articulan por la existencia de un diseño proyectual organizado en torno al pes romano y a medidas más pequeñas divisores de la misma como el unci y el palmus.

\section{BIBLIOGRAFÍA}

ABAD CASAL, L. 1977: «Arte y artistas en la España romana», Bellas Artes 77, 55.

ABAD CASAL, L. 1982 a: Pintura romana en España, (2 vol.) Universidad de Alicante.

ABAD CASAL, L. 1982 b: «Aspectos técnicos de la pintura mural romana». Anales de la Universidad de Alicante, 1.

ARIAS PÁRAmo, L. 1990: Estudio planimétrico de la Iglesia de San Julián de los Prados (Oviedo) a escala 1:20. Consejería de Educación y Cultura del Principado de Asturias. Oviedo.

ARIAS PÁRAMO, L. 1990: «Trazados geométricos previos a la labra en el prerrománico asturiano: las celosías de la iglesia de Sta. Cristina de Lena». A ESPA, 63. Madrid pp. 227-247.

ARIAS PÁRAMO, L. 1991: Trazados previos en la pintura mural de la iglesia de San Julian de los Prados (Con un estudio planimétrico de la iglesia de Santullano a escala 1:40, integrado por 12 planos). Fundación Museo Evaristo Valle. Gijón.

August1, S. 1957: La technique de la pinture pompeienne. Napoli.

BANGo TORVISO, J. 1988: «Alfonso II y Santullano» II Jornadas sobre Arte Prerrománico y Románico en Asturias. Villaviciosa.

BARBET, Alix. 1985: La peinture murale romaine. París.

BARBET, A. y ALLAG, C. 1972: «Techniques de préparation des parois dans la peinture murale romaine». MEFRA, 84.

BONET CORREA, A. 1980: Arte Prerrománico Asturiano. Barcelona.

BRUYNE, EDGAR de. 1987: La estética de la Edad Media. Madrid.

CAGIANO DE ACEVEDO, M. 1949: «La tecnica dei pittori romani» BICR, 3-4. 
CAGIANO DE: ACEVEDO, M. 1958: «Tecniche della pittura parietale antica». BICR, 33.

CenNinI, Cennino. 1971: /l libro dell'Arte (2 vol.). Vicenza.

DOERNER, M. 1962: Los materiales de pintura y su empleo en el arte. Barcelona.

DoDWE1.1. C. R. 1961: Theophilus. De Diversis artibus. Londres.

EASTLAKE, Charles Lock. 1967: Materials and Methods of painting of the Great Schools and Masters. (2 vol.). New York.

FERNANDEZ OCHOA, C. 1982: Asturias en la época romana. Madrid.

FONTAINE, J. 1978: El Prerrománico. Madrid.

HAWTHORNE, J. G. y SMITH, C.S. 1979: On divers arts. New York.

HEATH, T. L. 1956: The Thirteen Books of Euclid's Elements. New York.

ISIDORO DE SEVILLA. 1983: Etimologías. (2 vol.) Madrid.

LAURIE, A. P. 1910: Greck and Roman Methods of Painting. Cambridge.

LAURIE, A. P. 1914: The Pigments and Mediums of the Old Masters. Londres.

LAURIE, A. P. 1967: The Painter's Methods and materials. New York.

LOUMYER, G. 1920: Les traditions techniques de la peinture médievale. Bruselas.

MALTESE, C. y otros. 1980: Las técnicas artísticas. Madrid.

MORA, P. 1967: «Proposte sulla tecnica della pittura murale romana». BICR.

MORTET, V. 1907: «Un formulaire du VIII siècle pour les fondations d'edifices et de ponts». Bulletin Monumental.

NiEto AlCAIDE, V. 1989: Arte Prerrománico Asturiano. Salinas (Asturias).

Nieto PRieto, F. J. 1977: «Los esquemas compositivos de la pintura mural romana de Ampurias». Actas XIV. Zaragoza.

PANOFSKY, E. 1975: Renacimiento y renacimientos en el arte occidental. Madrid.

PLinio SEgundo, C. 1947-53: Histoire Naturelle. (6 vol.) Paris

REINACH, A. 1921: Textes grecs et latins relatifs à l'histoire de la peinture ancienne. París.

Selgas, F. 1916: La Basílica de San Julián de los Prados. Madrid.

SCHLUNK, H. y BERENGUer, M. 1957: La Pintura mural asturiana de los siglos IX y X. Oviedo.

SUREDA, J. 1985: La pintura románica en España. Madrid.

THEOPHILE. 1980: Essai sur divers arts. París.

THOMPSON, DANIEL V. 1956: The materials and techniques of medieval painting. Nueva York.

VITRUVIO POLION. 1787: De Archîtectura. Madrid.

VITRUVIO POLıÓN. 1985: Los diez libros de arquitectura. Traducción, prólogo y notas por Agustín Blánquez. Barcelona

WINDFIELD, D. C. 1968: «Middle and Later Byzantine Wall Painting Methods». DOP, XXII.

YARZA, J. 1984: Arte y Arquitectura en España. Madrid. 